OPEN ACCESS

Edited by:

Jon Pittman,

University of Manchester, UK

Reviewed by:

Christina Kühn,

Humboldt University of Berlin,

Germany

YiMa,

University of Connecticut, USA

*Correspondence:

Sylvain La Camera

sylvain.la.camera@univ-poitiers.fr

Specialty section:

This article was submitted to

Plant Traffic and Transport,

a section of the journal

Frontiers in Plant Science

Received: 23 September 2016 Accepted: 30 November 2016 Published: 20 December 2016

Citation:

Veillet $F$, Gaillard $C$

Coutos-Thévenot $P$ and La Camera $S$ (2016) Targeting the AtCWIN1 Gene

to Explore the Role of Invertases in Sucrose Transport in Roots and during Botrytis cinerea Infection.

Front. Plant Sci. 7:1899. doi: 10.3389/fpls.2016.01899

\section{Targeting the AtCWIN1 Gene to Explore the Role of Invertases in Sucrose Transport in Roots and during Botrytis cinerea Infection}

\author{
Florian Veillet, Cécile Gaillard, Pierre Coutos-Thévenot and Sylvain La Camera *
}

Laboratoire Ecologie et Biologie des Interactions, Equipe "SEVE-Sucres et Echanges Végétaux-Environnement," UMR Centre National de la Recherche Scientifique 7267, Université de Poitiers, Poitiers, France

Cell wall invertases (CWIN) cleave sucrose into glucose and fructose in the apoplast. CWINs are key regulators of carbon partitioning and source/sink relationships during growth, development and under biotic stresses. In this report, we monitored the expression/activity of Arabidopsis cell wall invertases in organs behaving as source, sink, or subjected to a source/sink transition after infection with the necrotrophic fungus Botrytis cinerea. We showed that organs with different source/sink status displayed differential CWIN activities, depending on carbohydrate needs or availabilities in the surrounding environment, through a transcriptional and posttranslational regulation. Loss-of-function mutation of the Arabidopsis cell wall invertase 1 gene, AtCWIN1, showed that the corresponding protein was the main contributor to the apoplastic sucrose cleaving activity in both leaves and roots. The CWIN-deficient mutant cwin 1-1 exhibited a reduced capacity to actively take up external sucrose in roots, indicating that this process is mainly dependent on the sucrolytic activity of AtCWIN1. Using T-DNA and CRISPR/Cas9 mutants impaired in hexose transport, we demonstrated that external sucrose is actively absorbed in the form of hexoses by a sugar $/ \mathrm{H}^{+}$ symport system involving the coordinated activity of AtCWIN1 with several Sugar Transporter Proteins (STP) of the plasma membrane, i.e., STP1 and STP13. Part of external sucrose was imported without apoplastic cleavage into cwin1-1 seedling roots, highlighting an alternative AtCWIN1-independent pathway for the assimilation of external sucrose. Accordingly, we showed that several genes encoding sucrose transporters of the plasma membrane were expressed. We also detected transcript accumulation of vacuolar invertase (VIN)-encoding genes and high VIN activities. Upon infection, AtCWIN1 was responsible for all the Botrytis-induced apoplastic invertase activity. We detected a transcriptional activation of several AtSUC and AtVIN genes accompanied with an enhanced vacuolar invertase activity, suggesting that the AtCWIN1-independent pathway is efficient upon infection. In absence of AtCWIN1, we postulate that intracellular sucrose hydrolysis is sufficient to provide intracellular hexoses to maintain sugar homeostasis in host cells and to fuel plant defenses. Finally, we demonstrated that Botrytis cinerea possesses its own functional sucrolytic machinery and hexose uptake system, and does not rely on the host apoplastic invertases.

Keywords: cell wall invertase, sugar transport, sucrose, Arabidopsis thaliana, Botrytis cinerea, source/sink relationship, CRISPR/Cas9 


\section{INTRODUCTION}

Higher plants have the ability to use atmospheric $\mathrm{CO}_{2}$ and solar energy to produce organic compounds, mainly in the form of sugar. As sugar production only takes place in green tissues, sugar partitioning occurs between photosynthetically active leaves that produce excess of photoassimilates and heterotrophic sink organs that are dependent on the continuous supply of sugars by the sources (Ainsworth and Bush, 2011). In most plants, carbon assimilated in sources is translocated throughout the plant via the phloem complex as a form of sucrose to provide carbon, and energy for growth and synthesis of storage (Lemoine et al., 2013). As many different sinks compete for carbohydrate at the same time, sucrose partitioning is regulated according to the individual sink strength which is defined as the ability of heterotrophic organs to import, process, and store photoassimilates (Herbers and Sonnewald, 1998; Ainsworth and Bush, 2011).

At the cellular level, sucrose is a key carbon source for many physiological processes, i.e., growth, development, and defense, and its role as signaling molecule is well established (Koch, 2004; Rolland et al., 2006; Ruan, 2014). The metabolism of sucrose produces hexoses, which provide carbon skeletons for primary metabolism (Koch, 2004; Bolouri-Moghaddam et al., 2010). In higher plants, two classes of enzymes catalyze the cleavage of sucrose. Sucrose synthases (EC 2.4.1.13) need UDP to reversibly cleave sucrose into UDP-glucose and fructose. By contrast, invertases (EC 3.2.1.26) irreversibly catalyze sucrose cleavage into glucose and fructose (Roitsch and González, 2004). Depending on their $\mathrm{pH}$ optimums and subcellular localizations, invertases have been classified into three classes (Ruan, 2014). Cell wall invertases (CWIN) are enzymes ionically bound to the cell wall with an acidic optimum $\mathrm{pH}$ of 3.5-5 (Roitsch and González, 2004). Vacuolar (VIN) and cytoplasmic invertases (CIN) are soluble enzymes with an acidic $(\mathrm{pH} 5.0-5.5)$ and neutral $(\mathrm{pH}$ 6.8-8.0) optimum pH, respectively (Roitsch and González, 2004). Plant invertases are encoded by small gene families with specific temporal and spatial expression patterns (Ruan, 2014). They are tightly regulated from transcriptional to posttranslational levels, particularly in response to environmental stimuli (Ruan, 2014). CWINs and VINs are subjected to posttranslational control by small proteins $(15-23 \mathrm{kDa})$ that have been characterized as specific inhibitors of $\beta$-fructosidases (INH) (Link et al., 2004; Rausch and Greiner, 2004; Hothorn et al., 2010; Su et al., 2016).

A wide range of regulatory roles has been proposed for cell wall invertases (Roitsch and González, 2004). By degrading sucrose in sinks, cell wall invertases participate to the osmotic gradient between source and sink that drives the long-distance transport of assimilates from source leaves into sink organs (Lemoine et al., 2013). Therefore, the function of cell wall invertases is essential for the regulation of phloem unloading and sink strength establishment.

Several studies have pointed out the crucial role played by some invertases and INHs in growth and development. Altered CWIN activity severely impacts reproductive organs that are often symplasticaly isolated from the surrounding environment. For example, mutations in ZmCWIN2, OsCWIN2 (OsGIF1), and SlCWIN1 (Lin5) lead to the production of miniature seeds, a decrease in grain yield and an altered flower and fruit morphology, respectively (Cheng et al., 1996; Wang et al., 2008; Zanor et al., 2009). In Arabidopsis, atcwin4 mutant flowers did not produce nectar but accumulated more starch and less soluble sugars (Ruhlmann et al., 2010). CWIN activity also has a strong impact on the normal plant development. Antisense repression of DcCWIN1 or DcVIN1 genes in carrot leads to impaired growth and development with elevated levels of sucrose and starch in aerial tissues and reduced carbohydrate content in roots (Tang et al., 1999). VIN genes are known to play a major role in generating hexoses in fruits. For example, impaired expression of SlVIN1 in tomato leads to $30 \%$ smaller fruits with higher sucrose content (Klann et al., 1996). Using a QTL approach, Sergeeva et al. (2006) identified AtVIN2 as a regulator of root elongation. Unlike CWINs and VINs, the role of CINs in plant physiology is not well understood, although some studies have pointed out their role in root growth in Arabidopsis, rice and Lotus japonicus (Jia et al., 2008; Barratt et al., 2009; Welham et al., 2009).

On the other hand, numbers of studies have described the induction of CWIN expression and/or activity in response to various pathogens (Proels and Hückelhoven, 2014; Tauzin and Giardina, 2014). Pathogen-induced CWIN activity generates important modifications in plant carbon partitioning, i.e., reduction of the photosynthesis, hexose accumulation in the apoplast, then limiting long distance sucrose export, and creation of an additional sink competing with other sinks (Scharte et al., 2005; Biemelt and Sonnewald, 2006; Berger et al., 2007; Schultz et al., 2013). Differential level of CWIN activity may affect plant resistance. In rice, constitutive overexpression of the cell wall invertase gene GRAIN INCOMPLETE FILLING 1 enhances resistance against both the bacteria Xanthomonas oryzae pv. Oryzae and the fungus Magnaporthe oryzae (Sun et al., 2014). In tobacco, RNA interference of CWIN genes LIN6 and LIN8 results in an increased susceptibility to the oomycete Phytophtora nicotianae (Essmann et al., 2008a). By contrast, the overexpression of INHs in Arabidopsis roots, resulting in the reduction of CWIN activity, leads to reduced symptoms of clubroot disease caused by the obligate biotrophic protist Plasmodiophora brassicae (Siemens et al., 2011).

Contrasting impacts of CWINs on plant resistance indicate that the additional pool of free hexoses generated by the activity of apoplastic invertases may be beneficial for both the pathogen and the host. For the former, these sugars represent a source of energy allowing growth and reproduction whereas for the latter, sugars can fuel the costly induction of defense mechanisms and act as signaling molecules to regulate defense gene expression (Herbers et al., 1996; Roitsch, 1999; Bolton, 2009; Bolouri Moghaddam and Van den Ende, 2012). The competition for available sugars is crucial for the outcome of the interaction (Lemoine et al., 2013). Depending on their mode of colonization, pathogens use different and complex strategies to favor infection. For example, the hemibiotrophic bacteria $X$. campestris pv. vesicatoria delivers type III effector XopB to interfere with CWIN activity and suppress sugar-induced defense responses in pepper leaves (Sonnewald et al., 2012). Obligate pathogens grow in the apoplast of living tissues and divert host metabolism by complex strategies of suppression or avoidance of plant defenses. 
Biotrophs mainly rely on the sugars transferred from the host via specialized feeding structures (Hall and Williams, 2000; Panstruga, 2003; Sutton et al., 2007). By contrast, necrotrophs kill host cells using an arsenal of secreted virulence factors, including toxins (van Kan, 2006; Laluk and Mengiste, 2010). They feed on dead tissues by macerating host organic polymers using cell wall degrading enzymes (Kubicek et al., 2014).

Free hexoses released by the activity of CWINs are retrieved either by host or pathogen cells through the activity of plasma membrane sugar transporters. Inductions of hexose transporter expression and/or activity have been reported in several plantpathogen interactions (Azevedo et al., 2006; Sutton et al., 2007; Lemonnier et al., 2014). In response to the biotrophic fungus Erysiphe cichoracearum, the increased CWIN activity is associated with the coordinated induction of the cell wall invertase gene AtCWIN1 and the Sugar Transporter Protein (STP) gene STP4 (Fotopoulos et al., 2003). The same coregulation of the Hexose Transporter VvHT5 and a cell wall invertase has been observed in grapevine infected with biotrophic fungi (Hayes et al., 2010). In response to the necrotrophic fungus B. cinerea, the induction of the Arabidopsis hexose transporter STP13 is required for the plant basal resistance (Lemonnier et al., 2014). Conversely, sugar transporters of the SWEET family that function as facilitators of sugar efflux can be targeted by pathogens to acquire sugars for their own growth (Chen et al., 2010; Chong et al., 2014; Chandran, 2015).

To gain access to carbohydrates from the host, pathogens also possess their own cell wall invertases and hexose transporters, allowing them to compete for resources (Doidy et al., 2012). However, for most of the pathosystems, it has not been possible to discriminate the contribution of plant or fungus to the increased invertase activity (Voegele and Mendgen, 2011). Voegele et al. (2006) identified the invertase Uf-INV1 from the rust fungus Uromyces fabae and Ruiz and Ruffner (2002) detected a fungal invertase in grape infected with $B$. cinerea. Several pathogen sugar transporters have also been identified. The hexose transporter UfHXT1 from $U$. fabae has been described to preferentially transport glucose with high affinity (Voegele et al., 2001), while hexose transporters of the hemibiotrophic pathogen Colletotrichum graminicola (CgHXT1-5) displayed different enzymatic properties (Lingner et al., 2011). Botrytis cinerea possesses a multigenic hexose uptake system, including the fructose $\mathrm{H}^{+}$/symporter named BcFRT1 (Doehlemann et al., 2005) and a family of 17 putative hexose transporters, named BcHXTs (Dulermo et al., 2009).

In this study, we examined cell wall invertase activities in A. thaliana organs exhibiting different source/sink status, and in leaves infected by the necrotrophic fungus $B$. cinerea. The expression of cell wall invertase and invertase inhibitorencoding genes has been analyzed in normal conditions and upon infection. The insertional mutation of the Arabidopsis cell wall invertase 1 gene, AtCWIN1, revealed that the corresponding protein AtCWIN1 was the major contributor to the CWIN activity in both leaves and roots, and was responsible for all the Botrytis-induced CWIN activity. We used the CWIN-deficient mutant $c$ win 1-1 as a tool to explore the role of cell wall invertases in the root assimilation of external sucrose and in the mechanism of apoplastic sucrose retrieval by the host during leaf infection. We proposed a model involving two different pathways for apoplastic sucrose absorption into plant cells. The major pathway depends on the AtCWIN1-mediated sucrose degradation and the coordinate activity of hexose-specific transporters, while an alternative pathway likely involves sucrose transporters and intracellular sucrose cleavage. The importance of both pathways for normal growth and resistance to pathogen is discussed. We further explored the assimilation of sugars by $B$. cinerea, demonstrating that the acquisition of host hexoses occurs via functional sucrolytic machinery and a multigenic hexose uptake system.

\section{MATERIALS AND METHODS}

\section{Plant Materials and Growth Conditions}

The wild type Arabidopsis thaliana was ecotype Columbia (Col-0). For soil culture of Arabidopsis plants, seeds were sown in an autoclaved mix of compost/vermiculite (3/1) and placed into a growth chamber under a $10 \mathrm{~h}$ light $\left(22^{\circ} \mathrm{C}\right) / 14 \mathrm{~h}$ dark $\left(18^{\circ} \mathrm{C}\right)$ photoperiod, with a $65 \%$ relative humidity. Experiments were performed on 5-6 week-old plants. Fully expanded leaves were used for sampling. Roots were separated from soil by multiple careful washings with water before sampling. For in vitro culture, seeds were sterilized and sown on half-strength Murashige and Skoog (MS) plates containing $0.8 \%$ agar and supplemented or not with $2 \%$ sucrose. Plates were kept in the dark for 2 days at $4{ }^{\circ} \mathrm{C}$ and then placed at $22^{\circ} \mathrm{C}$ under a $16 / 8 \mathrm{~h}$ light/dark photoperiod. Roots from 9-day-old seedlings were sampled.

The stp13-2 (salk_021204) and cwin1-1 (salk_091455) mutant lines were obtained from the SALK T-DNA insertion mutant collection (Alonso et al., 2003). Plants homozygous for the mutation were identified by PCR. The stp13-2 and STP13OE6 mutant lines were previously described in Lemonnier et al. (2014) and $d d e 2-2$, defective in the allene oxide synthase gene, was characterized in von Malek et al. (2002).

\section{Cloning Procedures}

Complete coding sequence of AtSTP1 was obtained after a PCRamplification of cDNA made from Arabidopsis leaves (Phusion Taq Polymerase, Thermo Scientific). Primers for amplification were listed in Supplementary Table 1. PCR products were cloned into the pENTR-D-TOPO vector (Invitrogen), sequenced and LR-recombined with pB2GW7 destination vector (Karimi et al., 2002) to express AtSTP1 under the control of the CaMV35S promoter. This construct was transferred into Agrobacterium tumefaciens strain GV3101 (pMp90) by heat shock. Wild type Col-0 plants were transformed using the floral dipping method (Clough and Bent, 1998) and transgenic homozygous T3 lines were selected according to their Basta resistance.

\section{Generation of Genetically Modified Arabidopsis Plants Using the CRISPR/Cas9 Genome Editing System}

The AtSTP1 gene was targeted using the CRISPR/Cas9 system (Jinek et al., 2012) using a protocol adapted from Fauser et al. (2014). CRISPR PLANT (Xie et al., 2014) and RGEN TOOLS 
(Park et al., 2015) softwares were used to design a $20 \mathrm{bp}$ spacer sequence complementary to a region located in the third exon of AtSTP1 gene (Supplementary Figure 1A, Supplementary Table 1). This sequence was inserted into the BbsI restriction site of the pEn-Chimera plasmid (Fauser et al., 2014). The customized sgRNA cassette was then transferred into the pDe-Cas9 vector (Fauser et al., 2014) using a single site Gateway LR reaction. The resulting plasmid was transferred into A. tumefaciens GV3101 (pMp90) strain by heat shock for subsequent floral dipping transformation in Col-0 plants (Clough and Bent, 1998). Primary transformants (T1) were selected according to their Basta resistance.

To genotype AtSTP1 lines, genomic DNA was extracted from $100 \mathrm{~T} 2$ plants coming from 2 independent $\mathrm{T} 1$ lines. The detection of the T-DNA was performed by PCR using primers located on the Cas 9 gene (Supplementary Table 1). 26 T-DNA-free plants were selected and tested for the presence of mutations in the target locus by High Resolution Melting-curve (HRM) analysis (data not shown). Three plants exhibiting divergent meltingcurves from the wild type were regarded as edited, and mutations were confirmed via Sanger sequencing (BigDye Terminator v3.1, Applied Biosystems). Mendelian inheritance of mutations and lack of the T-DNA were confirmed in T3 generation by sequencing and basta resistance (Supplementary Figure 1B). A single line showing a homozygous mutation in the AtSTP1 gene was selected and named $C R$-stp1. The genome edition resulted in an insertion of a single nucleotide, leading to a frameshift in the coding sequence (Supplementary Figure 1B). We identified 5 loci that harbored some similarities with the target locus using RGEN TOOLS (Bae et al., 2014) and off-target potential was assessed by HRM (Supplementary Figures 1D,E). Primers used are listed in Supplementary Table 1.

\section{Culture of B. cinerea, Infection Methods, and Fungal Quantification}

B. cinerea strain B05.10 (Staats and van Kan, 2012) was grown on Difco potato dextrose agar (Becton-Dickinson) at $22^{\circ} \mathrm{C}$ under a $16 / 8 \mathrm{~h} \mathrm{light/dark} \mathrm{photoperiod.} \mathrm{Conidia} \mathrm{were} \mathrm{harvested} \mathrm{in} \mathrm{sterile}$ water, filtered through miracloth (EMD Chemicals) and diluted to the appropriate concentration in quarter-strength potato dextrose broth (PDB; Becton-Dickinson).

For sugar uptake assays, liquid culture of $B$. cinerea was performed by cultivating $10^{4}$ conidia $\mathrm{ml}^{-1}$ in sterile 6-well culture plates (Nunclon Delta Surface, Thermo Scientific) containing $3 \mathrm{ml}$ of Gamborg B5 medium ( $\mathrm{pH}$ 5.8) supplemented with $2 \%$ sucrose. Plates were placed at $22^{\circ} \mathrm{C}$ under a $16 \mathrm{~h} / 8 \mathrm{~h}$ light/dark photoperiod with orbital shaking for $24 \mathrm{~h}$. For disease assays, plants were drop-inoculated on source leaves with 6 $\mu l$ of the conidia suspension $\left(5 \times 10^{4}\right.$ conidia $\left.\mathrm{ml}^{-1}\right)$ and the diameter of resulting lesions was measured after 3 days. For gene expression analysis and enzymatic activities, the entire rosette was sprayed with the conidia suspension $\left(5 \times 10^{4}\right.$ conidia $\mathrm{ml}^{-1}$ ) or, as a control, with quarter-strength potato dextrose broth without conidia. For fungal growth measurement, $6 \mu \mathrm{l}$ of the conidia suspension $\left(5 \times 10^{4}\right.$ conidia $\left.\mathrm{ml}^{-1}\right)$ were spotted on mature leaves. Ten $8 \mathrm{~mm}$ diameter disks from
3 plants were harvested at the indicated time points. DNA extraction and PCR analysis of $i A S K$ and cutA genes were performed as described by Gachon and Saindrenan (2004). After inoculation, plants were placed in a tray closed under saturating humidity and softened light. Infected source leaves were harvested at the indicated time points and frozen in liquid nitrogen.

\section{DNA Extraction and HRM Analysis}

DNA from $A$. thaliana plants was extracted using the Smart Extract kit (Eurogentec) or the NucleoSpin Plant II (MachereyNagel) according to manufacturer instructions. HRM analysis was performed using the LightCycler ${ }^{\circledR} 480$ II system, the High Resolution Melting Master and the LightCycler ${ }^{\circledR} 480$ Gene Scanning Software (Roche Life science).

\section{RNA Extraction and Real-Time Quantitative PCR (RT-qPCR) Analysis}

Total RNA was extracted from frozen ground $A$. thaliana materials using TRIzol reagent (Invitrogen) according to the manufacturer instructions. For soil-grown root samples, extraction was performed as described by Kay et al. (1987). RNA quantity and quality were verified using a Multiskan GO plate reader (Thermo Fischer) and an agarose gel. Total RNA was treated with DNAse I (Sigma-Aldrich) and reverse transcription was performed using M-MLV reverse transcriptase (Promega). Real-time quantitative PCR was carried out using the GoTaq qPCR Master Mix (Promega) with a Mastercycler realplex ${ }^{2}$ instrument (Eppendorf). For Arabidopsis target gene expression, results were normalized with the average of the $\mathrm{Ct}$ value of two reference genes, At4g26410 and AtACTIN2 (At3g18780), previously described as stable genes (Czechowski et al., 2005; Lemonnier et al., 2014). For B. cinerea target gene expression, results were normalized to the expression of the BcTUBA gene (Bc1g05600) (Dulermo et al., 2009). The results were expressed as relative gene expression according to the $2^{-\Delta \mathrm{Ct}}$ method described by Schmittgen and Livak (2008). Primers have been designed using Primer3 (Untergasser et al., 2012) in conjunction with Netprimer (www.premierbiosoft.com/netprimer) and tested for their specificity and efficiency $(\geq 90 \%)$. Sequences of the primers used in this study are listed in Supplementary Table 2.

\section{Determination of Invertase Activities}

Total extracts were made by mixing ground samples with $700 \mu \mathrm{l}$ of ice-cold extraction buffer (50 mM HEPES, $1 \mathrm{mM}$ EDTA, $5 \mathrm{mM}$ DTT, and $1 \mathrm{mM}$ PMSF). Soluble and insoluble fractions were separated by centrifugation at $20,000 \mathrm{~g}$ for $15 \mathrm{~min}$ at $4^{\circ} \mathrm{C}$. The supernatant was used for cytoplasmic (CIN) and vacuolar (VIN) invertase activities measurements. The pellet was washed three times and then resuspended in $500 \mu \mathrm{l}$ of the extraction buffer for the CWIN activity determination. Sucrolytic activities were assayed by adding samples in the incubation buffer containing $100 \mathrm{mM}$ sucrose and $100 \mathrm{mM}$ sodium acetate buffered at $\mathrm{pH}$ 4 for apoplastic activity and $\mathrm{pH} 5$ for vacuolar activity. For CIN activity, samples were mixed with $100 \mathrm{mM}$ sucrose and $25 \mathrm{mM}$ HEPES ( $\mathrm{pH}$ 7). The mixture was incubated at $30^{\circ} \mathrm{C}$ 
for 60 or $90 \mathrm{~min}$ and stopped by the addition of the stop solution ( $1 \mathrm{M}$ sodium potassium tartrate, $1 \%$ 3,5-dinitrosalicylic acid and $0.5 \mathrm{M} \mathrm{KOH}$ ). Samples were incubated at $95^{\circ} \mathrm{C}$ for $10 \mathrm{~min}$ and cooled to room temperature before absorbance measurements at $560 \mathrm{~nm}$ using a microplate reader (Multiskan GO, Thermo Fischer). Results were normalized to the fresh weight.

\section{Radiolabeled Sugar Uptake in Arabidopsis Seedlings and Botrytis Mycelium}

Five entire seedlings (6-day-old) or seedling roots (9-dayold) were placed for $45 \mathrm{~min}$ in Petri dishes containing the equilibration buffer (20 mM MES-KOH pH 5.8, $1 \mathrm{mM} \mathrm{CaCl}_{2}$ ) under agitation. After equilibration, samples were transferred into the incubation buffer $\left(20 \mathrm{mM}\right.$ MES pH 5.8, $1 \mathrm{mM} \mathrm{CaCl}_{2}$, $0.2 \mathrm{mM}$ glucose or sucrose) containing radiolabeled sugars $\left(0.1 \mu \mathrm{Ci} . \mathrm{ml}^{-1}\right.$ of $\left[{ }^{14} \mathrm{C}\right]$-glucose or $\left[{ }^{14} \mathrm{C}\right]$-sucrose $)$ for $45 \mathrm{~min}$ under agitation.

A liquid culture of Botrytis mycelium was washed twice and incubated for $45 \mathrm{~min}$ in equilibration buffer (Gamborg B5, $20 \mathrm{mM}$ MES-KOH pH 5.8) under agitation. Incubation buffer containing unlabeled sucrose $(0.2 \mathrm{mM})$ and $\left[{ }^{14} \mathrm{C}\right]$-sucrose $\left(0.1 \mu \mathrm{Ci} . \mathrm{ml}^{-1}\right)$ was added to the mixture and incubated for 30 min under agitation.

After incubation, samples were washed three times for $2 \mathrm{~min}$ in equilibration buffer. Samples were left overnight in the digestion buffer (36.4\% perchloric acid w/v, $0.017 \%$ triton $\mathrm{X}-100 \mathrm{w} / \mathrm{v}$ and $8.1 \%$ hydrogen peroxide $\mathrm{w} / \mathrm{v}$ ) at $60^{\circ} \mathrm{C}$. Incorporated radioactivity was determined by liquid scintillation counting (Tri-Carb 2910 PR, PerkinElmer). To measure CCCPinsensitive sugar uptake, CCCP $(20 \mu \mathrm{M})$ was added into the equilibration buffer $10 \mathrm{~min}$ before addition of incubation buffer. For competition experiments, competitive unlabelled sugars ( $4 \mathrm{mM}$ for sucrose and mannitol, $2 \mathrm{mM}$ each for glucose and fructose in 1:1 mixture) were added in 20-fold excess together with radiolabeled sugars in the incubation buffer.

\section{Soluble Sugar Analysis}

Frozen ground $A$. thaliana materials were serially extracted (three times) in methanol/chloroform/water $(60 / 25 / 15, \mathrm{v} / \mathrm{v} / \mathrm{v})$. The mixture was centrifuged at $1800 \mathrm{~g}$ for leaf extracts or $5000 \mathrm{~g}$ for root extracts for $10 \mathrm{~min}$ at $20^{\circ} \mathrm{C}$. Supernatants were pooled and mixed with $1.8 \mathrm{ml}$ of water and centrifuged at $1200 \mathrm{~g}$ for $15 \mathrm{~min}$ at $20^{\circ} \mathrm{C}$. The supernatant was collected and evaporated in a centrifugal vacuum evaporator (MiVac QUATTRO concentrator) at $50^{\circ} \mathrm{C}$ for $3 \mathrm{~h}$. The soluble glucose, fructose and sucrose contents of sample extracts were measured using the Sucrose/DFructose/D-Glucose Assay Kit (Megazyme) according to the manufacturer instructions.

\section{Statistical Analyses}

Statistical analyses were performed using the GraphPad Prism version 7.00 for Mac, GraphPad Software, La Jolla California USA, www.graphpad.com.

\section{RESULTS}

\section{Cell Wall Invertase Activity and Gene Expression in A. thaliana Organs with Different Source/Sink Status}

Cell wall invertases (CWINs), that mediate the sucrose cleavage into hexoses in the apoplast, are key players in plant carbon partitioning between source and sink organs. Our first aim was to quantify the level of CWIN activity in different organs of Arabidopsis plants and to identify AtCWIN gene(s) that could be responsible for these CWIN activities. Insoluble fractions of protein extracts were assayed for CWIN activity in mature leaves and roots from adult soil-grown plants, and in roots grown in vitro (Figure 1A). These organs were chosen because they are indicative for different source/sink status. Plants grown in soil are representative of an autotrophic situation, in which typical source/sink relationship occurs with source leaves supplying photoassimilates to carbon sinks (i.e., roots). In heterotrophic situation as in vitro culture, roots can retrieve carbohydrates directly from the medium and export them to other parts of the plant. In this case, one can suppose that the source/sink balance is modified compared to the autotrophic situation (Wolf et al., 1998).

Roots of soil-grown A. thaliana displayed CWIN activity that was significantly 2 -fold higher than in leaves (Figure 1A). The higher CWIN activity in roots is consistent with a role of CWIN in the creation of a gradient of sucrose between source and sink. Strikingly, in the presence of non-limited sucrose availability in the culture medium, the level of CWIN activity in roots grown in vitro was 6-fold higher than the one of soil-grown roots (Figure 1A). To identify genes that could contribute to these CWIN activities, we monitored the expression profile of genes encoding functional CWINs (Figure 1B). In Arabidopsis genome, among the 6 annotated AtCWIN genes, only AtCWIN1, -2, -4, and -5 encode functional proteins with CWIN activity, since AtCWIN3 and -6 were found to be fructan exohydrolases (FEH) (De Coninck et al., 2005). AtCWIN2 and -4 transcripts were not detected in leaves and roots, which is in agreement with a previous study showing their specific expression in reproductive tissues (Wang and Ruan, 2012). In source leaves, AtCWIN1 was the most expressed AtCWIN gene whereas AtCWIN5 transcripts were barely detected. Both genes were expressed in soil-grown roots at a detectable level (Figure 1B). In concordance with data from enzymatic activity, we found that the expression of AtCWIN1 in roots cultured in vitro was approximately 10-fold higher compared to roots grown in soil (Figure 1B).

To address a potential posttranslational regulation, we monitored the expression of AtCIF1 and AtC/VIF2 genes encoding specific invertase inhibitor proteins (INHs) (Link et al., 2004; Su et al., 2016). In source leaves, we observed a high accumulation of $A t C /$ VIF2 transcripts whereas in roots, both genes were expressed at similar low levels (Figure 1C).

Taken together, these data showed a strong correlation between AtCWIN1 expression profile and CWIN activities in the different organs we tested. This will contribute to the assumption that CWIN activity is transcriptionally regulated, with a major role of AtCWIN1. In source leaves, the low level of CWIN 

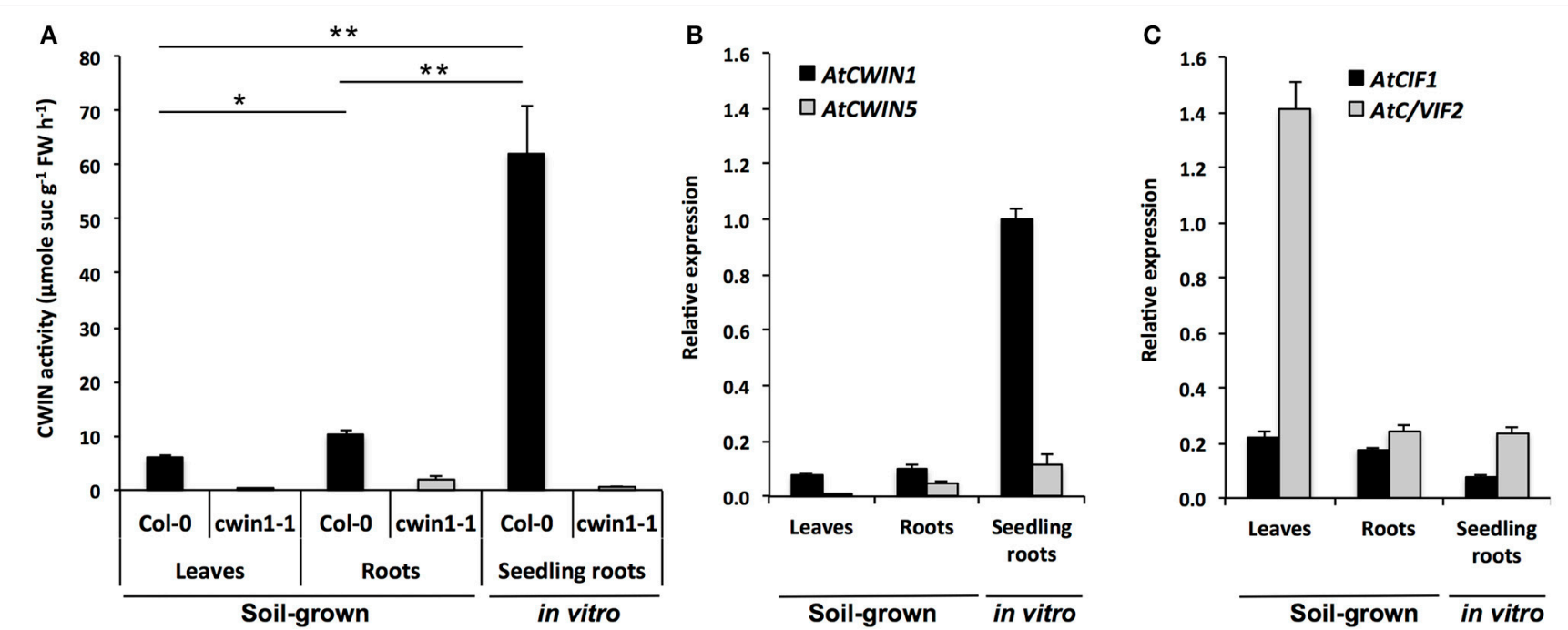

FIGURE 1 | Cell wall invertase activity and gene expression in different Arabidopsis organs. (A) CWIN activity in Col-0 and $\mathrm{CWin} 1-1$ was assayed from frozen ground tissues of 5-6 week-old soil-grown plants (leaves and roots) or 9-day-old seedling roots. Data represent mean ( \pm SE) of 2 (seedling roots) or 3 (leaves and roots) independent experiments. (B,C) Relative gene expression of AtCWIN1, AtCWIN5 (B), AtCIF1 and AtC/VIF2 (C) genes was performed by RT-qPCR and results were normalized to the plant reference genes At4g26410 and AtACTIN2 (At3g18780). Data represent mean ( \pm SE) of 3 independent experiments. AtCWIN2 and -4 are not presented because transcript levels were below the detection threshold. For (A), asterisks represent significant differences between organs of Col-0 plants (Student's $t$-test, ${ }^{*} P<0.05 ;{ }^{* \star} P<0.01$ ).

activity is probably maintained by the posttranslational activity of invertase inhibitors, such as AtC/VIF2. Collectively, it indicates that organs with different source/sink status displayed differential CWIN activities, which can be correlated with carbohydrate needs or availabilities in the surrounding environment.

\section{AtCWIN1 is Essential for Cell Wall Invertase Activities in A. thaliana Roots and Leaves}

To investigate the contribution of the AtCWIN1 protein to the overall CWIN activity in leaves and roots, we isolated a homozygous T-DNA mutant (cwin1-1), impaired in AtCWIN1 expression (Supplementary Figure 2). As seen in Figure 1A, CWIN activity was completely abolished in cwin 1-1 source leaves and dramatically reduced in roots grown in soil and cultured in vitro. These results demonstrate that AtCWIN1 is responsible for all the CWIN activity in source leaves and is the major contributor to this activity in roots. The residual CWIN activity measured in cwin1-1 roots likely involved the low participation of an additional CWIN protein, which is probably AtCWIN5 according to the transcriptional data (Figure 1B).

\section{AtCWIN1-Mediated CWIN Activity Regulates Sugar Retrieval from the Surrounding Environment}

To gain insight into the regulatory role of CWIN activity in the assimilation of carbohydrates by sink organs, we further investigated the sugar absorption of 9-day-old seedling roots grown on MS medium (Figure 2). In this condition, we previously showed that CWIN activity is very high and almost totally dependent on AtCWIN1 (Figure 1A). When grown with sucrose as the sole carbon source, Col-0 roots displayed a substantial initial rate of $\left[{ }^{14} \mathrm{C}\right]$-sucrose uptake $\left(108 \pm 24 \mathrm{nmol} \mathrm{g}^{-1} \mathrm{FW} 45 \mathrm{~min}^{-1}\right.$ ) (Figure 2A). Radiolabeled sucrose retrieval by roots was mainly driven by an active sugar $/ \mathrm{H}^{+}$symport system since it was almost totally inhibited by the protonophore carbonylcyanide $\mathrm{m}$-chlorophenyl hydrazine (CCCP) (Figure 2A). In these assays, we were not able to determine the proportion of radiolabeled sucrose that was imported as such and the one of radiolabeled hexoses formed by the cell wall invertase activity prior root absorption. To find answers, we took advantage of the availability of the cwin1-1 mutant impaired in the apoplastic sucrose cleavage. Experiments of $\left[{ }^{14} \mathrm{C}\right]$-sucrose assimilation showed that $c$ win 1-1 seedling roots exhibited a $65 \%$ reduction of the total $\left[{ }^{14} \mathrm{C}\right]-$ uptake compared to Col-0 roots (Figure 2B). Since cwin1-1 roots exhibited a total glucose uptake rate that was very similar to Col-0 roots (Figure $2 \mathrm{C}$ ), these results suggest that most of the external sucrose is converted into hexoses by the activity of AtCWIN1 before absorption into Col-0 root cells. Because external sucrose was substantially absorbed in the form of hexoses, it implies the coordinated activity of hexose-specific plasma membrane carriers to transport them from the apoplast to the cytosol. Yamada et al. (2011) previously showed that hexose $/ \mathrm{H}^{+}$transporters, belonging to the Sugar Transporter Protein (STPs) family, play important roles in roots during the absorption of monosaccharides from the rhizosphere. AtSTP1 and AtSTP13 were major contributors to this process under normal conditions and in response to environmental stresses. Then, we monitored the expression of the 14 AtSTP-encoding genes in our experimental conditions. According to Yamada et al. (2011), we found that only 4 AtSTP genes (AtSTP1, -4, 


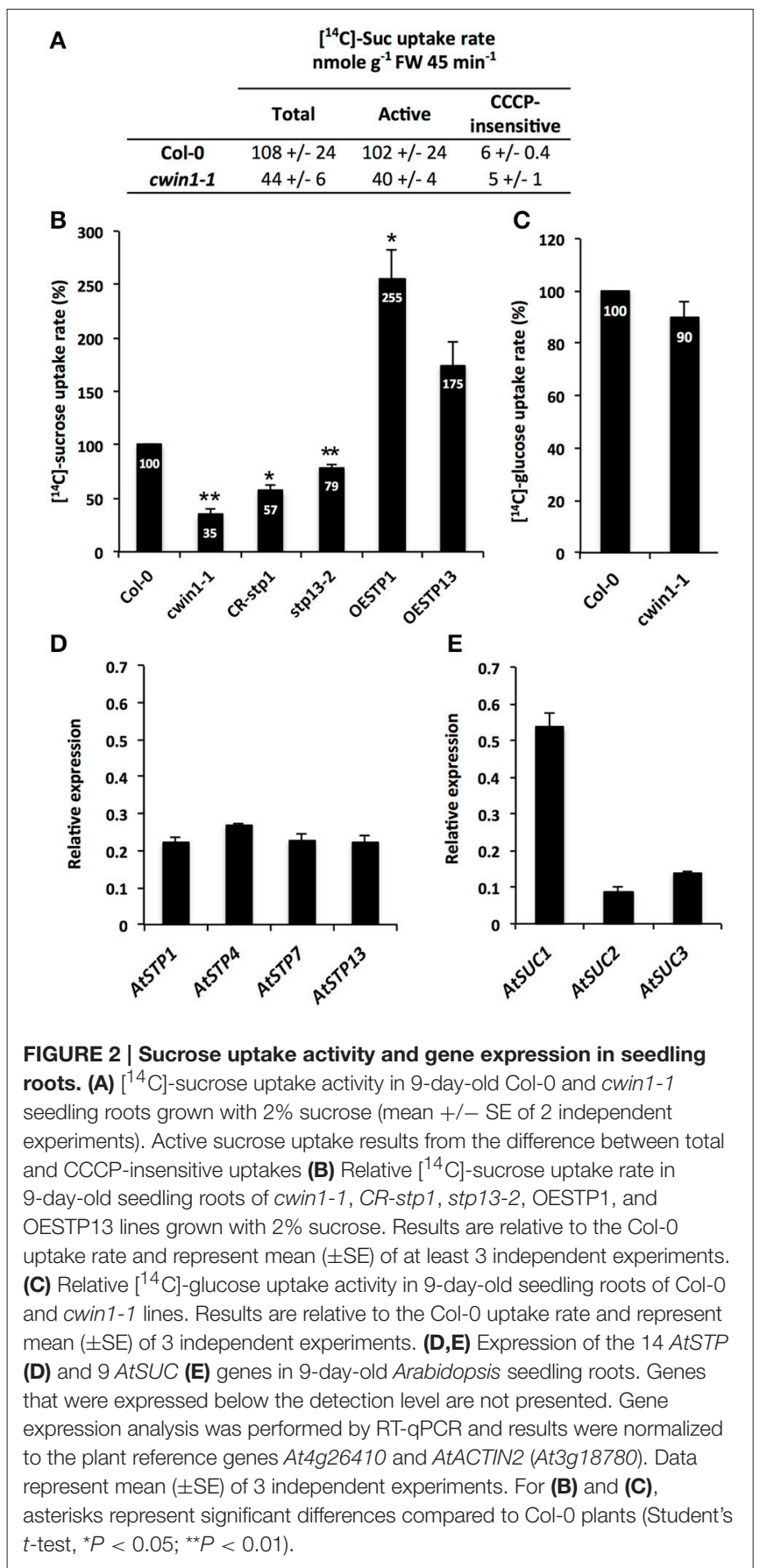

-7 , and -13) were expressed to a detectable level, although they displayed similar transcript levels in our conditions (Figure 2D).

To explore the involvement of AtSTP1 and -13 in $\left[{ }^{14} \mathrm{C}\right]-$ sucrose retrieval, we analyzed transgenic lines with AtSTP1- or AtSTP13-mediated alterations of glucose uptake activities. We previously reported in Lemonnier et al. (2014) that the T-DNA insertion mutant stp13-2 and the AtSTP13-overexpressing line (OESTP13) exhibited a $30 \%$ reduction or a 3 -fold increase in glucose absorption compared to wild type, respectively. Here, we also generated plants constitutively expressing the complete
AtSTP1 coding sequence under the control of the CaMV35S promoter (OESTP1) and plants with a CRISPR/Cas9-mediated AtSTP1 gene disruption (CR-stp1) (Supplementary Figure 1). In comparison with wild type, CR-stp1, and OESTP1 lines displayed a $40 \%$ decrease and a 3 -fold increase of glucose uptake rates, respectively (Supplementary Figure 1C). When floated with $\left[{ }^{14} \mathrm{C}\right]$-sucrose, the amount of $\left[{ }^{14} \mathrm{C}\right]$-sugars that was taken up into CR-stp1 and stp13-2 roots was significantly reduced compared to wild type (Figure 2B). Taking into consideration that both AtSTP1 and 13 have been characterized as hexose-specific transporters with no sucrose transport activity (Sauer et al., 1990; Norholm et al., 2006; Büttner, 2007, 2010), these data strengthen our assumption that AtCWIN1 cleaves external sucrose into hexoses before their cellular absorption by hexoses-specific transporters. Conversely, roots of either AtSTP1- and STP13overexpressing lines showed increased $\left[{ }^{14} \mathrm{C}\right]$-sugar uptake rates (Figure 2B). These data suggest that the AtCWIN1-mediated sucrose conversion is fast enough to supply hexoses to roots of plants exhibiting increased hexose uptake activities (OESTP1 and -13 lines).

\section{An AtCWIN1-Independent Pathway for Root Absorption of External Sucrose}

Although CWIN activity was almost inexistent, the phenotypic analysis of cwin1-1 did not reveal any obvious alteration of growth or development when cultured in soil or on MS medium (supplemented or not with $2 \%$ sucrose) (Supplementary Figures 3A,B). The soluble sugar contents in cwin1-1 leaves and roots were also unchanged compared to wild type plants (Supplementary Figures 4A,B). This indicates that cwin1-1 mutant is able to compensate the lack or the strong reduction of the CWIN activity either in source or sink organs. Therefore, the residual sucrose uptake activity exhibited by cwin1-1 roots (Figure 2B) pointed out an alternative AtCWIN1-independent pathway for the assimilation of external sucrose. In such pathway, specific sucrose transporters should play a central role, which is supported by the detection of transcripts of 3 genes (AtSUC1, 2, and 3) encoding plasma membrane sucrose carriers (AtSUCs) in roots (Figure 2E). While AtSUC1 expression was long considered to be pollen specific (Stadler et al., 1999), recent studies revealed expression also in leaves and roots (Sivitz et al., 2007; Durand et al., 2016). These genes were recently identified as potential contributors for carbon export to the roots during water deficit (Durand et al., 2016). An AtCWIN1-independent pathway would also require a subsequent intracellular sucrose cleavage into hexoses for metabolic use. Since the vacuole constitutes a large reservoir for internal hexoses and sucrose (Nadwodnik and Lohaus, 2008; Hedrich et al., 2015), we further examined vacuolar invertases (AtVINs) in leaves, roots and in vitrocultured roots (Figure 3). Two genes are known to encode AtVINs in Arabidopsis genome, named AtVIN1 and AtVIN2 (Ruan, 2014). In our conditions, both genes were expressed with differential expression patterns (Figure 3A). Interestingly, rates of sucrose cleavage by VINs were higher than the ones of CWINs in all the organs we tested (Figures 1A, 3B) and were not modified in cwin1-1 mutant (Figure 3B). These data, together 

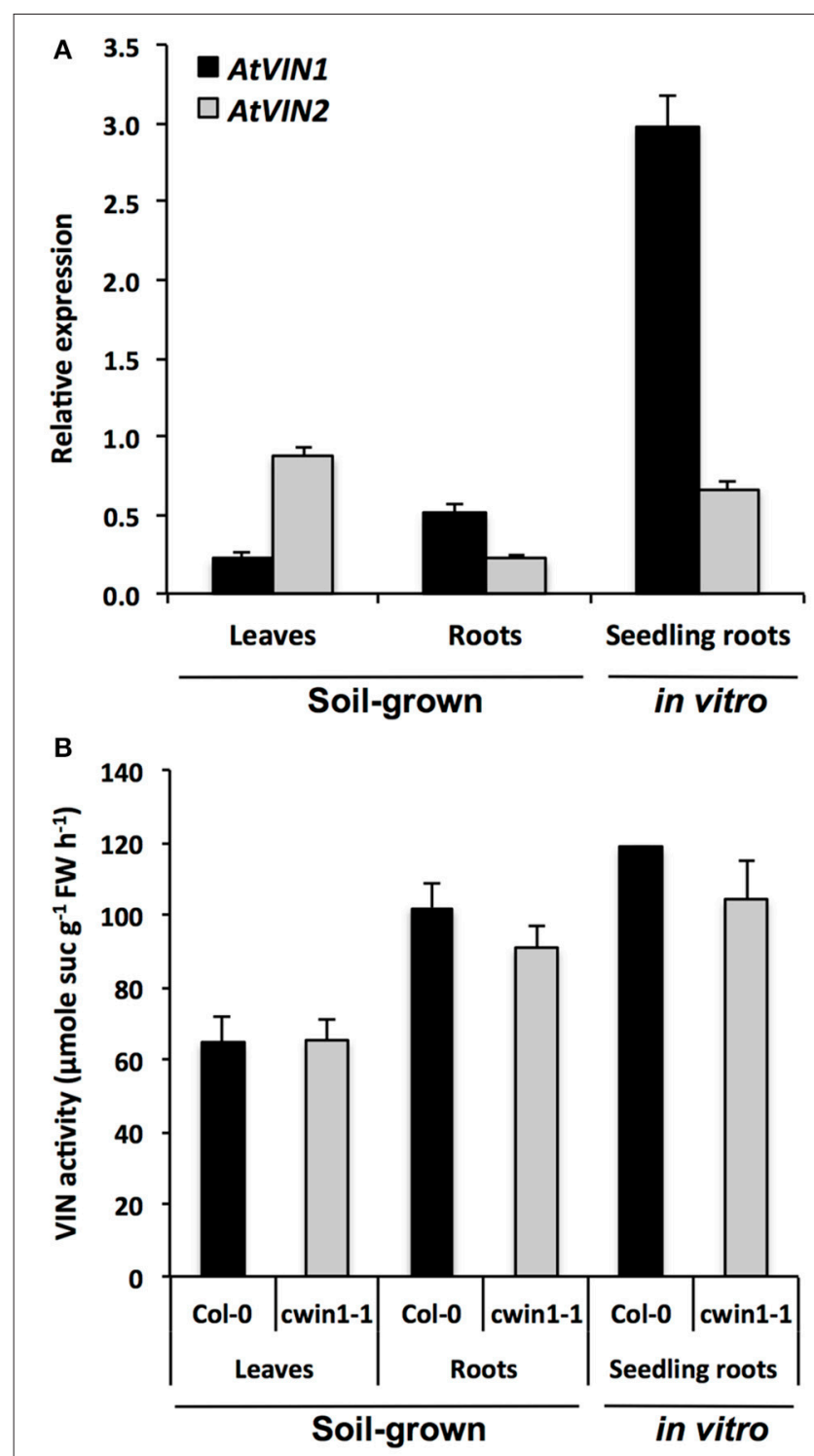

FIGURE 3 | Vacuolar invertase gene expression and activity in different Arabidopsis organs. (A) Relative gene expression of AtVIN genes was performed by RT-qPCR and results were normalized to the plant reference genes At4g26410 and AtACTIN2 (At3g18780). Data represent mean ( \pm SE) of 3 independent experiments. (B) VIN activity was assayed from frozen ground tissues of 5-6 week-old soil grown plants (leaves and roots) or 9-day-old seedling roots. Data represent mean $( \pm S E)$ of 2 (seedling roots) or 3 (leaves and roots) independent experiments. No significant difference was determined between Col-0 and cwin $1-1$ by a Student's $t$-test $(P<0.05)$.

with the normal soluble sugar content in cwin1-1 leaves and roots (Supplementary Figure 4), indicate that VIN activity may provide a substantial contribution to the internal free hexose generation and may therefore help to support the normal growth of CWIN-deficient plants.

To summarize, we demonstrated that there are two routes for the root absorption of sucrose from the surrounding environment. The major pathway is largely dependent on the sucrolytic activity of AtCWIN1 and requires the cooperation of
Sugar Transport Proteins, whereas the AtCWIN1-independent pathway likely involves SUC transporters and VIN activities.

\section{AtCWIN1 Expression is Responsible for the Botrytis-Induced CWIN Activity in Infected Leaves}

CWINs have also been described as key enzymes during plant pathogen/interactions (Schultz et al., 2013; Tauzin and Giardina, 2014). While the activation of CWIN gene expression and activity has been well documented in response to several biotrophic pathogens, there is little information concerning how CWINs impact the outcome of the interaction with necrotrophic fungi, such as B. cinerea (Berger et al., 2007; Tauzin and Giardina, 2014). To investigate whether CWIN proteins could play a role in response to $B$. cinerea, protein extracts from infected leaves were assayed for CWIN activity. Time course experiments revealed that infection with $B$. cinerea results in a 2 -fold increase of the CWIN activity from $48 \mathrm{~h}$ post-inoculation (hpi) compared to uninfected controls, with a 3 -fold induction peak after $72 \mathrm{~h}$ (Figure 4A). We further monitored the expression profile of genes encoding AtCWINs by RT-qPCR during the course of the infection. Solely AtCWIN1 was expressed and displayed a clear induction in leaves 48 and $72 \mathrm{~h}$ after infection (Figure 4B). Transcripts of the invertase inhibitor-encoding gene AtC/VIF2 decreased dramatically to weak level from $48 \mathrm{hpi}$, while the level of AtCIF1 expression was relatively weak and stable (Figure 4C). These results suggest that the invertase inhibitors have potentially a minor role in the control of the CWIN activity upon infection.

In cwin 1-1 mutant, inactivation of AtCWIN1 is accompanied by a dramatic reduction of the CWIN activity in control and infected leaves (Figure 4A). In this latter case, the Botrytisinduced increase in CWIN activity was totally abolished (Figure 4A). As the quantity of AtCWIN5 transcripts were detected at a negligible level (data not shown), these results stated that AtCWIN1 was responsible for all the Botrytis-induced increase in CWIN activity during the course of the infection. A low residual activity was measured in Botrytis-infected cwin1-1 leaf extracts (Figure 4A). Therefore, we cannot rule out a minor contribution of Botrytis CWINs.

In addition, we found that AtCWIN1 transcripts accumulated concomitantly with several Botrytis-responsive defense genes, i.e., AtPDF1.2, AtPR1, and AtPAD3 (Glazebrook, 2005) (Supplementary Figure 5) while symptoms of necrosis were visible (data not shown). Because AtCWIN1 is expressed once the interaction between both partners is well established, it likely suggests that it may participate to the transition of healthy sources into sink, by increasing the sink strength of infected leaves.

\section{Deficiency in CWIN Activity Does Not Alter Plant Basal Resistance to $B$. cinerea}

CWIN activity has been associated with plant resistance and defense mechanisms during several biotrophic and hemibiotrophic interactions (Herbers et al., 1996; Essmann et al., 2008a; Bonfig et al., 2010; Sun et al., 2014). The absence 


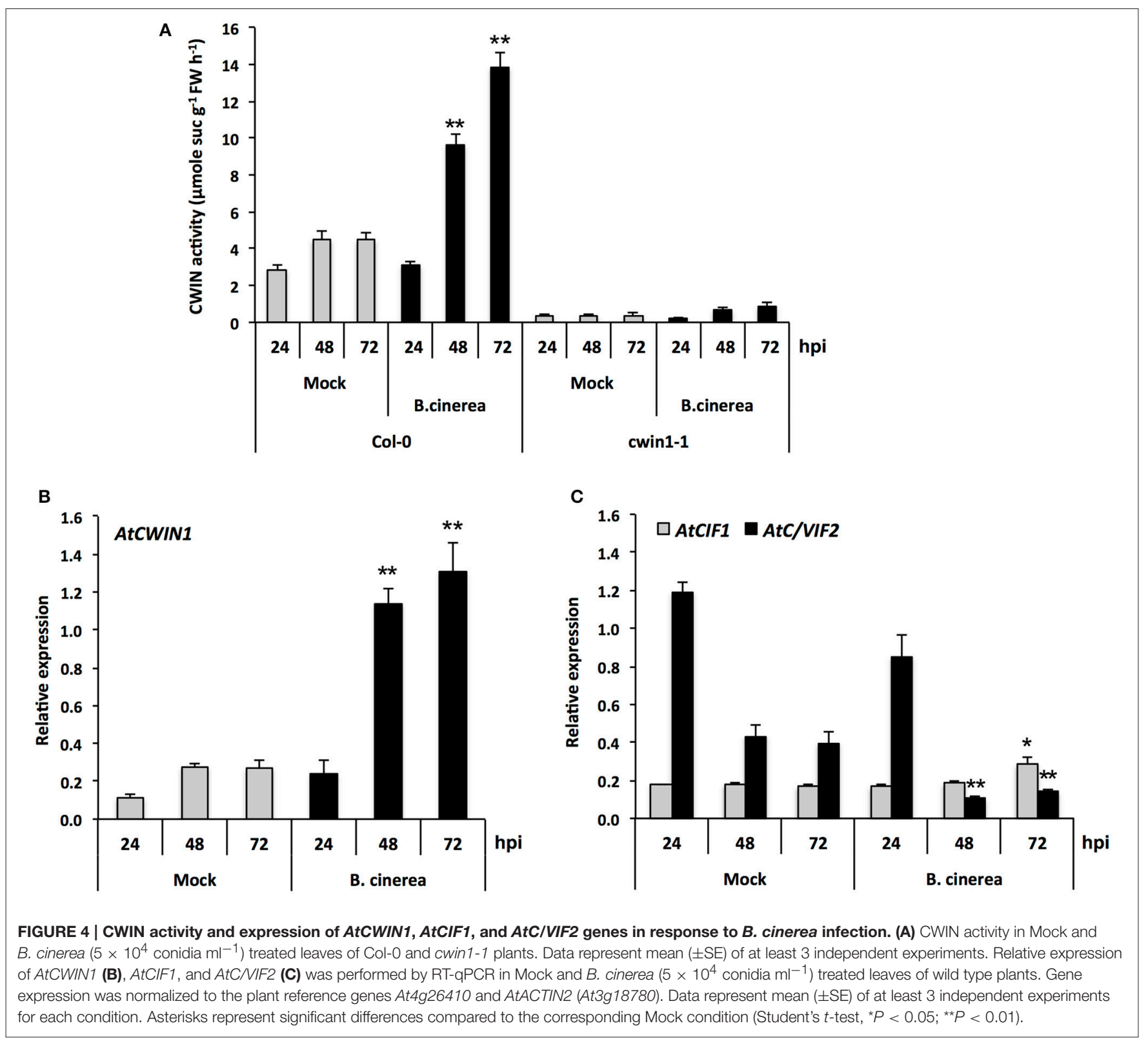

of Botrytis-induced CWIN activity in cwin1-1 (Figure 4A) prompted us to investigate the biological importance of AtCWIN1 in the outcome of B. cinerea infection. To this end, cwin1-1 plants were challenged with $B$. cinerea and tested for their susceptibility (Figure 5). Mature leaves were dropinoculated with a PDB solution containing conidia and the average diameter of resulting lesions was used as an indicator of disease susceptibility. The jasmonic acid-defective mutant dde2-2 was used as control for susceptible plants (von Malek et al., 2002; La Camera et al., 2011). As shown in Figure 5A, WT and cwin1-1 plants exhibited the same susceptibility to $B$. cinerea isolate B05.10, as no significant modification of lesion size has been measured between both genotypes. In addition, the induction pattern of several Botrytis-responsive genes did not differ from that observed in cwin1-1 (Supplementary Figure 5). Considering these results, we conclude that AtCWIN1 is not involved in the supply of hexoses for activation of the PAMPtriggered Immunity. We postulated that the suppression of the sucrose-degrading activity in cwin1-1 may alter the apoplastic sugar content at the site of infection and in turn affect the fungal development and pathogenicity. To assess this hypothesis, we monitored the fungal DNA content in leaves by real-time PCR during the course of the interaction (Gachon and Saindrenan, 2004). As seen in Figure 5B, the progression of B. cinerea in leaf tissues was similar in wild type and cwin1-1 plants. These data strongly support the assumption that AtCWIN1-related invertase activity is not a critical step to supply hexoses for pathogen nutrition. 


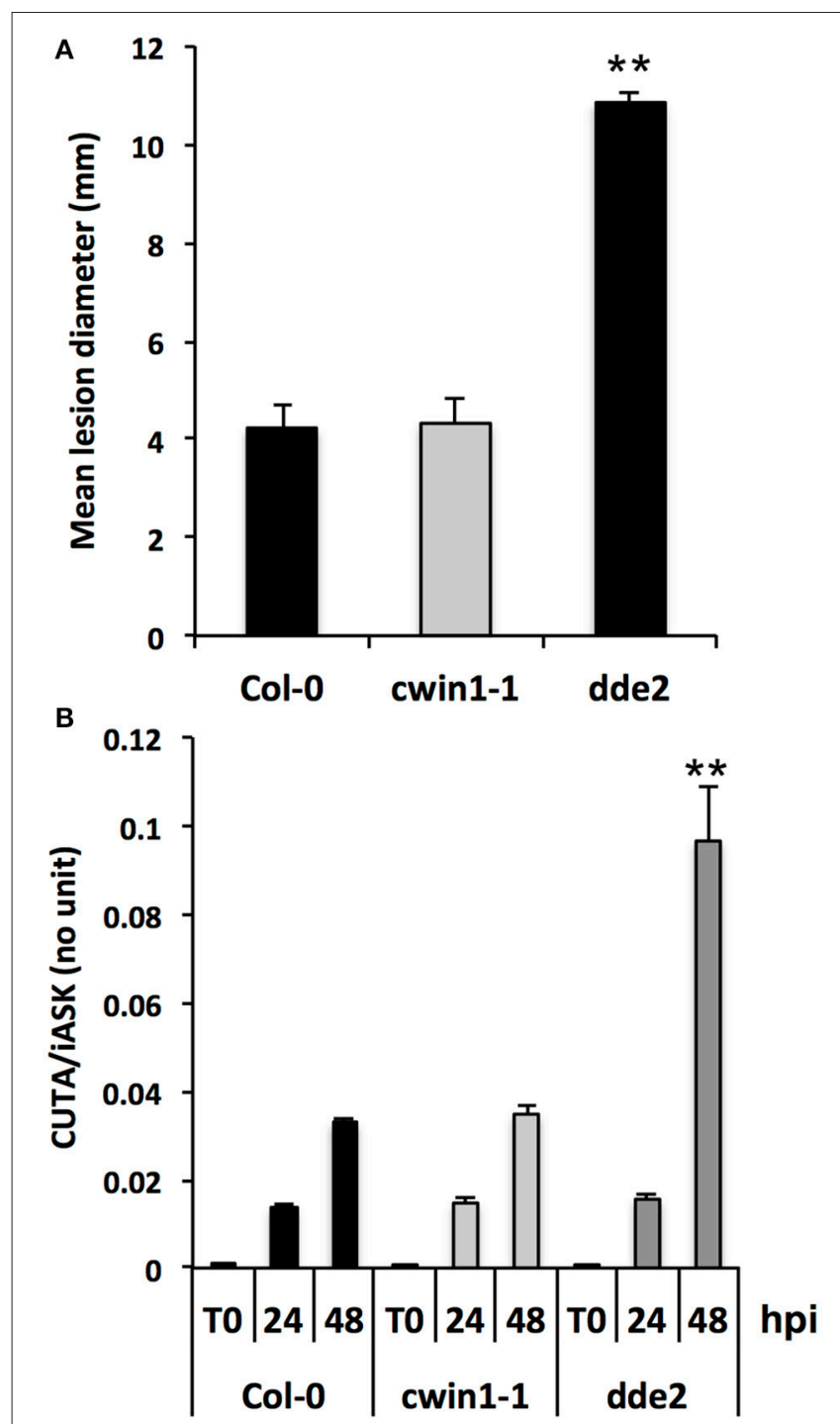

FIGURE 5 | Disease phenotype of Col-0 and cwin1-1 plants in response to $\boldsymbol{B}$. cinerea infection. (A) Lesion diameters measured 3 days after $B$. cinerea infection. Source leaves were drop-inoculated with a PDB solution containing $5 \times 10^{4}$ conidia $\mathrm{ml}^{-1}$. Data represent mean ( $\pm \mathrm{SE}$ ) of at least 3 independent experiments. (B) Quantification of in planta growth of $B$. cinerea. Foliar disks were cut around the infection point, and relative genomic DNA level was quantified by qPCR using B. cinerea CUTINASE and Arabidopsis iASK primers. Data represent mean ( $\pm \mathrm{SE}$ ) of 3 independent experiments. Asterisks represent significant differences compared to Col-0 plants (Student's t-test, $\left.{ }^{\star \star} P<0.01\right)$.

\section{Sucrose Transporters Expression and Intracellular Invertase Activity Are Induced after Infection with $B$. cinerea}

To provide additional clarification regarding how low level of CWIN activity in cwin1-1 did not impact plant basal resistance to $B$. cinerea, we investigated the alternative AtCWIN1independent sucrose cleavage that may occur in challenged leaves. To this end, we monitored activities of intracellular invertases, i.e., cytoplasmic (CIN) and vacuolar invertases
(VIN), during the course of $B$. cinerea infection. As shown in Figure 6A, intracellular sucrolytic activities were induced at 48 and $72 \mathrm{~h}$ post-inoculation compared to mock treatment. VIN were approximately four times higher than the ones related to CINs. We also pointed out that VINs mainly contributed to the increased intracellular invertase activities in challenged leaves (Figure 6A). This result was supported by the transcriptional activation of genes encoding vacuolar invertases, AtVIN1 at 48 and $72 \mathrm{hpi}$ and AtVIN2 at $72 \mathrm{hpi}$ (Figure 6B). We further examined VIN activity in cwin1-1 upon infection and found that vacuolar cleavage of sucrose was not affected, since it exhibited similar rates compared to wild type (Figure 6C). Collectively, these data strongly suggest that the high intracellular sucrolytic activity may supply free hexoses to cells undergoing PAMPTriggered Immunity, and to this extent largely compensates the apoplastic invertase deficiency caused by the inactivation of AtCWIN1. This assumption likely involved the activity of plasma membrane sucrose-specific transporters to move sucrose from the apoplasm into the cytosol. Then, we monitored the expression of sucrose transporters of the plasma membrane $48 \mathrm{~h}$ after challenge with $B$. cinerea. The expression of AtSUC1, 2, and 3 were detected, AtSUC2 transcripts being the most abundant (Figure 7). It is well established that AtSUC2 is expressed in the collection phloem of mature leaves, and is essential in phloem loading (Truernit and Sauer, 1995; Stadler and Sauer, 1996). Interestingly, levels of AtSUC1 and 3 transcripts were significantly increased upon B. cinerea infection whereas AtSUC2 expression was not affected (Figure 7). Expression patterns of AtSUCs were also similar in cwin1-1 (Figure 7). The expression of several SUC genes and the transcriptional up-regulation of some of them emphasized the putative role of these sucrose transporters in the cellular absorption of apoplastic sucrose into infected cells.

Collectively, these data suggest that sucrose uptake and its subsequent intracellular cleavage may constitute an efficient way to generate intracellular hexoses upon $B$. cinerea infection.

\section{B. cinerea Possesses a Sucrolytic Machinery and a Multigenic Hexose Uptake System for Plant Hexose Resorption}

The cleavage of apoplastic sucrose and the likely increase of the apoplastic pool of hexoses are potentially beneficial for the heterotrophic $B$. cinerea. In the present study, we have pointed out the probable involvement of BcCWINs in protein extracts from infected leaves, as a residual CWIN activity was detected in cwin1-1 infected plants (Figure 4A). To go further, we explored the insoluble (CWIN) and soluble (acidic and neutral) invertase activities from $B$. cinerea mycelium (Figure 8A). As it was technically unachievable to discriminate fungal material from host tissues during in vivo infection, protein fractions were extracted from a liquid culture of mycelium. In this condition, we were able to measure extracellular invertase activity and also to a lesser extent acidic and neutral invertase activities from the soluble protein fraction (Figure 8A). These results suggest two 


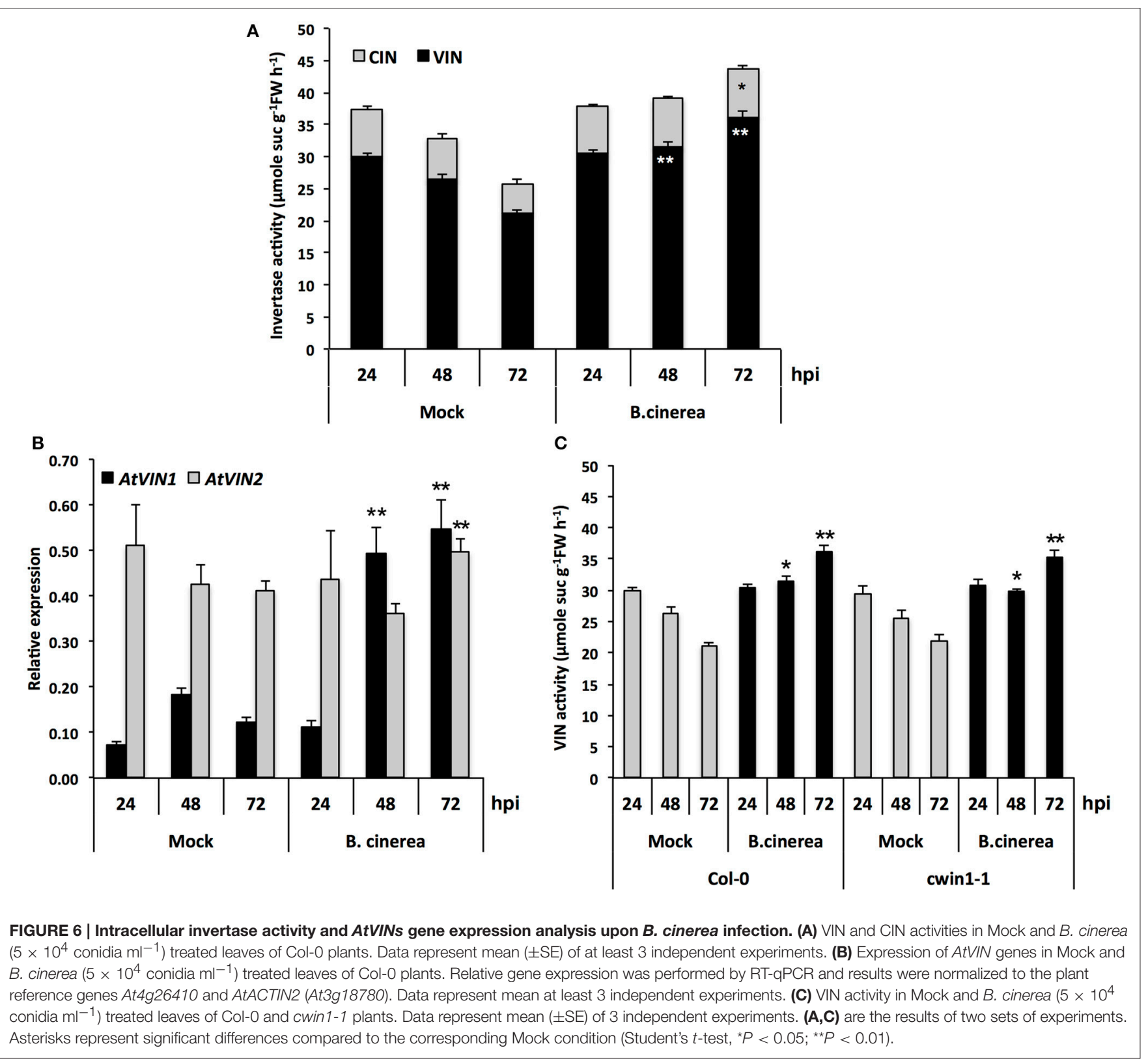

potential routes for apoplastic sucrose uptake. Using radiolabeled sucrose, we demonstrated that external sucrose that was taken up by fungal mycelium involved a sugar $/ \mathrm{H}^{+}$symport system as the protonophore CCCP inhibited almost $95 \%$ of total uptake (Figure 8B).

To investigate the CWIN dependency of the external sucrose uptake, we performed competition assays in which $\left[{ }^{14} \mathrm{C}\right]$-sucrose uptake into mycelium was tested with competing sugars supplied in a 20 -fold higher concentration. As seen in Figure 8C, $\left[{ }^{14} \mathrm{C}\right]$ sugar uptake rates were strongly reduced by an excess of sucrose, but also by an excess of a 1: 1 mixture of glucose and fructose. As a control, we showed that the polyol mannitol did not affect fungal sucrose uptake (Figure 8C). Because the competitive effect of sucrose on $\left[{ }^{14} \mathrm{C}\right]$-uptake was to the same extent as glucose/fructose ( 87 and $86 \%$ of inhibition, respectively, Figure 8C), we concluded that external sucrose is preferentially converted into hexoses by BcCWIN activities prior to be internalized. To date, there is no information regarding the identification of $B$. cinerea protein exhibiting CWIN activity. In our attempt to identify candidate gene(s) for such activity, we focused our interest on two genes, Bc1g10247 and Bc1g16010. These genes were identified by Parrent et al. (2009) after the analysis of the evolutionary history of the glycoside hydrolase family 32 (GH32) in 76 fungal genomes. According to conserved motifs, Bc1g10247 belongs to the GH32 group 1 with a putative extracellular invertase activity, whereas Bclg16010 is a member of the group 4 annotated as endo-inulinase (Parrent et al., 2009). We designed specific primers for both sequences and monitored 


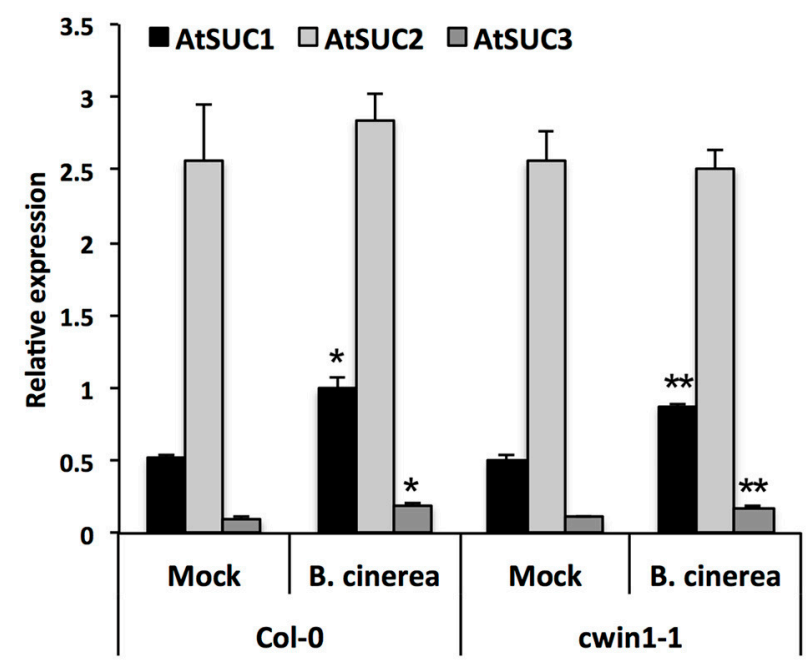

FIGURE 7 | Expression of AtSUC genes upon B. cinerea infection. Relative gene expression of AtSUC1, -2, -3, -4, and -5 was performed by RT-qPCR on $B$. cinerea treated leaves $\left(5 \times 10^{4}\right.$ conidia $\left.\mathrm{ml}^{-1}\right)$ of wild type and cwin 1-1 plants $48 \mathrm{~h}$ post-inoculation. Genes that were expressed below the detection level are not presented. Results were normalized to the plant reference genes At4g26410 and AtACTIN2 (At3g18780). Data represent mean ( \pm SE) of at least 2 independent experiments. Asterisks represent significant differences compared to the corresponding Mock condition (Student's t-test, $\left.{ }^{\star} P<0.05 ;{ }^{\star \star} P<0.01\right)$.

their expression by RT-qPCR during the course of infection of Arabidopsis leaves by $B$. cinerea (Figure 8D). No transcript was found for Bc1g16010, which was not surprising, as A. thaliana does not produce fructan (Ruan, 2014). By contrast, Bc1g10247 is expressed during the course of the interaction with $A$. thaliana (Figure 8D). As this gene is the sole annotated extracellular invertase in $B$. cinerea genome, this makes it a good candidate for this role.

Because sucrose was preferentially taken up in the form of hexoses by fungal cells (Figure 8C), we examined the expression pattern of Botrytis genes that were predicted to belong to the major facilitator superfamily of hexose transporters (Figure 8D). Dulermo et al. (2009) and Doehlemann et al. (2005) identified an extended gene family of hexose (17 $B c H X T s)$ and fructose-specific (BcFRT1) transporters. As shown in Figure 8D, hexose transporter genes displayed differential expression patterns during the course the infection, with three genes that were predominantly induced at $48 \mathrm{hpi}$, i.e., BcFRT1, $B c H X T 1,-6$, and two genes with a latter peak of expression, i.e., BcHXT7, and -11. These data are in line with the results demonstrating the capacity of Botrytis cells to import hexoses in vitro (Figure 8C). Three hexose transporter genes were also coexpressed with the putative extracellular invertase-encoding gene Bc1g10247 (Figure 8D). As Botrytis is able to degrade external sucrose (Figure 8A), these data point out a strong cooperation between $\mathrm{BcCWIN}(\mathrm{s})$ and a multigenic hexose uptake system for the retrieval of host sugars and provide strong support to the assumption that infection by pathogens creates a new sink.

\section{DISCUSSION}

\section{Role of CWIN Activity in Carbon Partitioning}

Because cell wall invertases are described as key regulators of the plant carbon partitioning and the sink strength, our first goal was to explore and compare the role of Arabidopsis cell wall invertases in organs behaving as source, sink or subjected to a source/sink transition. We found that CWIN activity was higher in roots than in leaves (Figure 1A), which is in agreement with the proposed role of root apoplastic invertases, thought to facilitate phloem unloading by maintaining a sucrose concentration gradient between source and sink organs (Ruan, 2014). Plants grown in vitro with an exogenous source of carbon are believed to be heterotrophic. In cultured potato plants, the analysis of $\mathrm{CO}_{2}$ assimilation showed that high sugar concentration in medium reduced the contribution of carbon derived from the photosynthesis to the plant growth (Wolf et al., 1998). In the present study, roots grown in heterotrophic condition displayed a very high CWIN activity (Figure 1A). In heterotrophic cell suspension culture of maize, metabolizable sugars, sucrose and glucose, were associated with the increased abundance of Incw 1 transcripts, the concomitant increased levels of INCW1 protein and enzyme activity (Cheng et al., 1999). Taken together, these data indicate that assimilation of external sugars via the increased activity of apoplastic invertases may help to compensate the reduced input of photoassimilates in roots. Considering that sucrose is known to act as signaling molecule (Rolland et al., 2002), it also indicates that sucrose availability in the medium probably modulates the level of CWIN activity by up regulating CWIN gene expression (Koch, 2004).

Numerous studies have reported an increase in CWIN activity upon pathogen challenges with bacteria, fungi, virus, oomycetes or nematodes (Proels and Hückelhoven, 2014; Tauzin and Giardina, 2014). In many pathosystems, CWIN induction is frequently accompanied by a reduction of the photosynthesis, an accumulation of soluble carbohydrates, and a reduction in carbon export from infected leaves, leading to an enhanced sugar flow toward the infection site (Scharte et al., 2005; Berger et al., 2007). Together, these changes in carbon partitioning suggest that pathogen infections lead to the establishment of a new sink competing with existing sinks (Schultz et al., 2013). The involvement of invertases during the interaction of plants with biotrophic pathogens is particularly well documented (Tauzin and Giardina, 2014). For example, the induction of AtCWIN1 was correlated with an increased CWIN activity upon infection with the biotrophic fungus E. cichoracearum (Fotopoulos et al., 2003). In grape, the cell wall invertase gene VvcwINV is also up regulated upon infection with downy and powdery mildews (Hayes et al., 2010). To date, few studies analyzed the role of CWIN during the interaction between plants and pathogens with a necrotrophic lifestyle. To address the specific case of necrotrophs, we challenged mature leaves with the fungus B. cinerea. Arabidopsis leaves inoculated with $B$. cinerea showed an increased CWIN activity during the course of the infection (Figure 4A). Ruiz and Ruffner (2002) reported such an induction of CWIN activity in infected grape berries and evidenced the 


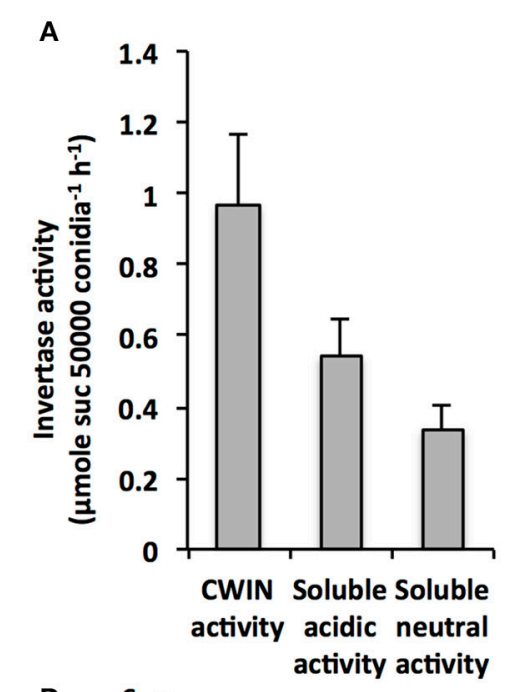

D
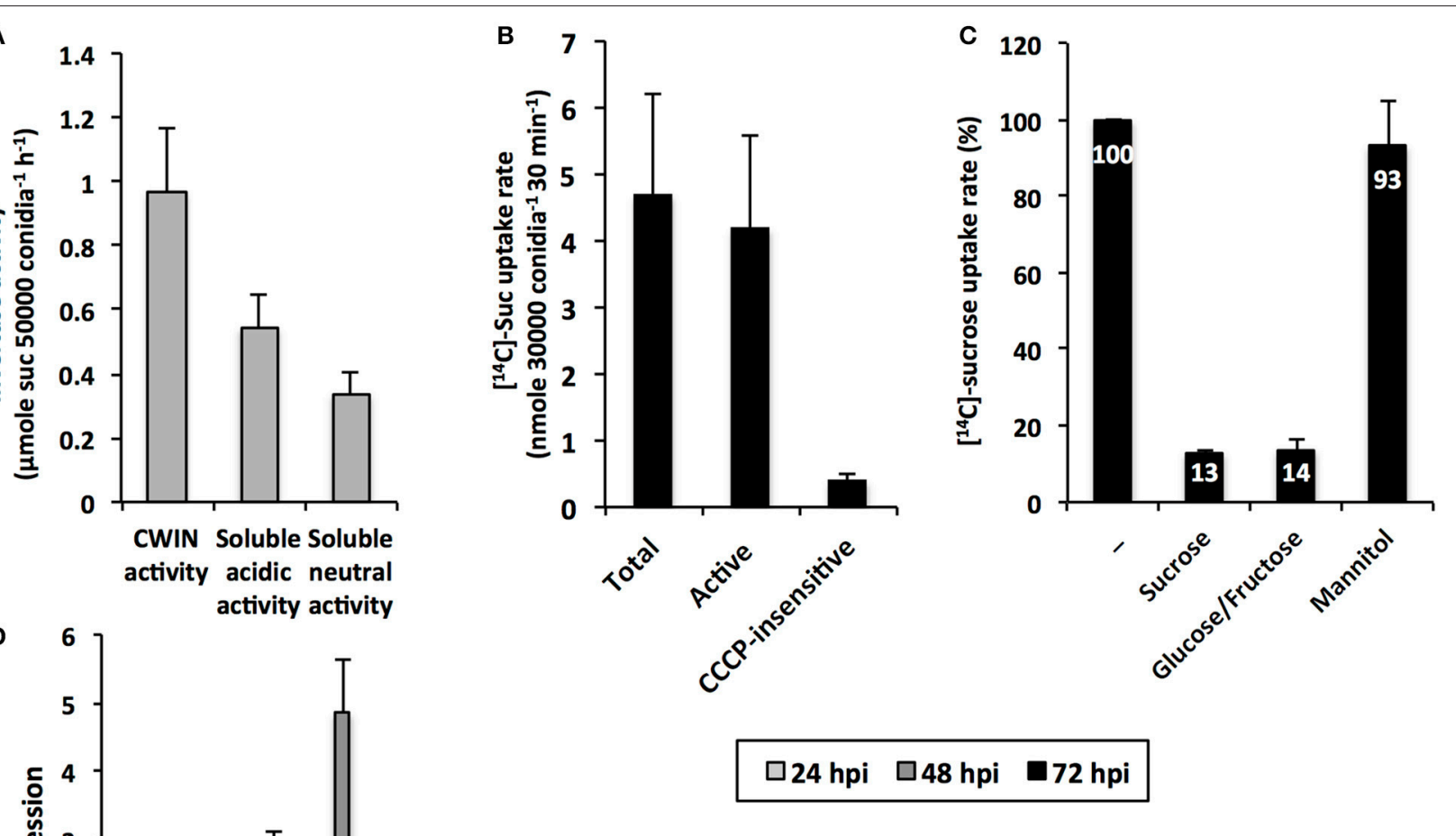

FIGURE 8 | B. cinerea invertase activity, sugar transport and gene expression (A) Cell wall and intracellular (acidic and neutral) invertase activities in B. cinerea mycelium grown in vitro (mean $+/-\mathrm{SE}$ of 3 independent experiments). (B) $\left[{ }^{14} \mathrm{C}\right]$-sucrose uptake activity in $B$. cinerea mycelium grown in vitro (mean $+/-\mathrm{SE}$ of 3 independent experiments). Active sucrose uptake results from the difference between total and CCCP-insensitive uptakes. (C) Inhibition of [ $\left.{ }^{14} \mathrm{C}\right]$-sucrose uptake activity by sucrose, glucose:fructose (1:1 mixture) and mannitol supplied in 20-fold excess in $B$. cinerea mycelium grown in vitro (mean $+/-$ SE of at least 2 independent experiments). (D) Relative expression of B. cinerea putative invertase (Bc1g10247 and Bc1g16010), fructose (BcFRT1) and hexoses transporter $(H \times t 1-17)$ genes in infected Arabidopsis leaves $\left(5 \times 10^{4}\right.$ conidia $\left.\mathrm{ml}^{-1}\right)$. Gene expression analysis was performed by RT-qPCR and results were normalized to the B. cinerea TUBA gene. Data represent mean ( $\pm \mathrm{SE}$ ) of 3 independent experiments.

contribution of fungal invertases. Interestingly, the absolute level of the Botrytis-induced CWIN activity in Arabidopsis leaves reached the one of roots (Figures 1A, 4A). Furthermore, this induction occurred at late stage, when the interaction with the fungus is well established. Altogether, our results suggest that leaf infection with the necrotrophic fungus $B$. cinerea may lead to a source/sink transition with the creation of a new sink. The question whether infected leaves may compete with other sinks for resources remains to be determined.

\section{Transcriptional and Post-translational Controls of CWIN Activity}

To identify molecular actors that may contribute to CWIN activity, we have conducted a transcriptional approach. Cell wall invertases, which belong to the GH32 hydrolases family, are encoded by a small multigenic subfamily. Transcriptional studies by RT-qPCR revealed that only two AtCWIN genes, AtCWIN1 and -5 , were expressed in leaves and roots (Figure 1B). According to Ruan (2014), AtCWIN-encoding genes form 2 groups, with a constitutive expression in all tissues for AtCWIN1 and AtCWIN5, and a predominant expression in reproductive organs for AtCWIN2 and AtCWIN4. Our results are in agreement with several reports indicating that ACWIN1 was highly expressed in source leaves (Sherson et al., 2003; Quilliam et al., 2006). In our experimental conditions, AtCWIN5 transcripts were barely detected which was different from the report made by Quilliam et al. (2006). Although the role of CWIN in sinks is well established, the expression pattern of AtCWINs genes in roots was not clearly defined. In this study, we have shown that both AtCWIN1 and -5 were expressed in soil-grown roots (Figure 1B). 
However, AtCWIN1 transcripts were largely predominant in roots cultured in heterotrophic condition. This latter result, together with the high CWIN activity, supports our hypothesis that CWIN activity is transcriptionally controlled by the sucrose abundance (Cheng et al., 1999). After challenge with B. cinerea, solely AtCWIN1 was up regulated (Figure 4B). It seems that transcriptional activation of this particular gene is part of a general response from the plant to environmental stimuli, since it has been shown that AtCWIN1 expression is stimulated under several biotic stresses (Chou et al., 2000; Fotopoulos et al., 2003; Bonfig et al., 2006; Siemens et al., 2011) and under abiotic stresses (Quilliam et al., 2006).

Many reports indicate that CWIN activity also depends on posttranslational regulation (Rausch and Greiner, 2004). To address this question, we monitored the expression of AtCIF1 and AtC/VIF2 genes encoding specific inhibitor proteins (Link et al., 2004; Su et al., 2016). Our results suggest that CWIN activity is maintained at a low level in healthy source leaves by a mechanism that likely involves the posttranslational activity of the invertase inhibitor AtC/VIF2. Upon Botrytis challenge, the transcriptional repression of $A t C / V I F 2$ is accompanied with the induction of AtCWIN1 gene expression (Figures $4 \mathbf{B}, \mathbf{C}$ ). As a consequence, the CWIN-mediated increase of sucrose cleavage is promoted in infected leaves. A similar mechanism of posttranslational control of CWIN activity through the repression of AtC/VIF2 has been reported in response to infection by $P$. syringae (Bonfig et al., 2010).

\section{AtCWIN1 Is Essential for CWIN Activity}

We analyzed the T-DNA insertion line cwin1-1 that displays an impaired expression of AtCWIN1 (Supplementary Figure 2B). In cwin1-1, leaf CWIN activity was completely abolished, whereas only a weak residual activity was detected in roots (Figure 1A), demonstrating the essential contribution of AtCWIN1 in apoplastic sucrose cleaving activity. In a previous study, Quilliam et al. (2006) reported that the insertional inactivation of AtCWIN1 led to only a $30-50 \%$ reduction in leaf CWIN activity. This apparent discrepancy may be due to the use of a different T-DNA insertion line (SAIL_258_A01). In the present work, we showed that $A t C W I N 1$ is the only AtCWIN gene induced under Botrytis attack and its inactivation leads to the complete loss of the Botrytis-induced increase in CWIN activity (Figure 4A), demonstrating its unique role upon infection. A similar loss of the wound induction of CWIN activity has been reported in $\Delta$ atcwin1 plants (Quilliam et al., 2006). Since responses to wounding and pathogens share overlapping signaling pathways (Fujita et al., 2006), it reinforces the hypothesis that CWINs regulate common stress responses of the plant (Roitsch et al., 2003).

\section{Different Routes for Sucrose Assimilation}

Because cwin1-1 plants exhibited a dramatically low rate of apoplastic sucrose cleavage, it provides an ideal tool to explore the regulatory role of CWIN activity in the assimilation of carbohydrate by sinks. Using 9-day-old roots cultured in vitro and radiolabeled sucrose uptake experiments, we were able to propose a model for sucrose retrieval from the surrounding environment (depicted in Figure 9). First, we showed that roots from cwin1-1 seedlings have reduced capacity to actively take up external sucrose (Figure 2B), indicating that this process is mainly dependent on the sucrolytic activity of AtCWIN1. Using T-DNA and CRISPR/Cas9 mutants impaired in hexose transport, we demonstrated that external sucrose is absorbed in the form of hexoses by a sugar $/ \mathrm{H}^{+}$symport system (Figure 2B). It involves several Sugar Transporter Proteins (STP) of the plasma membrane, i.e., STP1 and STP13, which are transcriptionally coexpressed with AtCWIN1 in roots. This is supported by the work of Yamada et al. (2011) showing that monosaccharide absorption by roots depends on the expression of STP 1 and -13. In agreement with our data, a rapid and efficient mechanism of sucrolysis before import has been reported in root tips using FRET glucose and sucrose nanosensors (Chaudhuri et al., 2008). Because plants overexpressing hexose-specific transporters exhibited an increased sucrose uptake rate (Figure 2B), we further showed that the AtCWIN1-dependent conversion of sucrose into glucose and fructose is a non-limiting step to supply hexose transporters with substrates.

Besides this AtCWIN1-dependent pathway, this study has also brought to light the involvement of a second route for the retrieval of external sucrose (Figure 9), since a substantial proportion of sucrose was imported into cwin1-1 seedling roots (Figure 2B). This AtCWIN1-independent pathway likely involves an active sucrose transport system, because sucrose uptake rate was almost totally abolished in cwin1-1 roots in

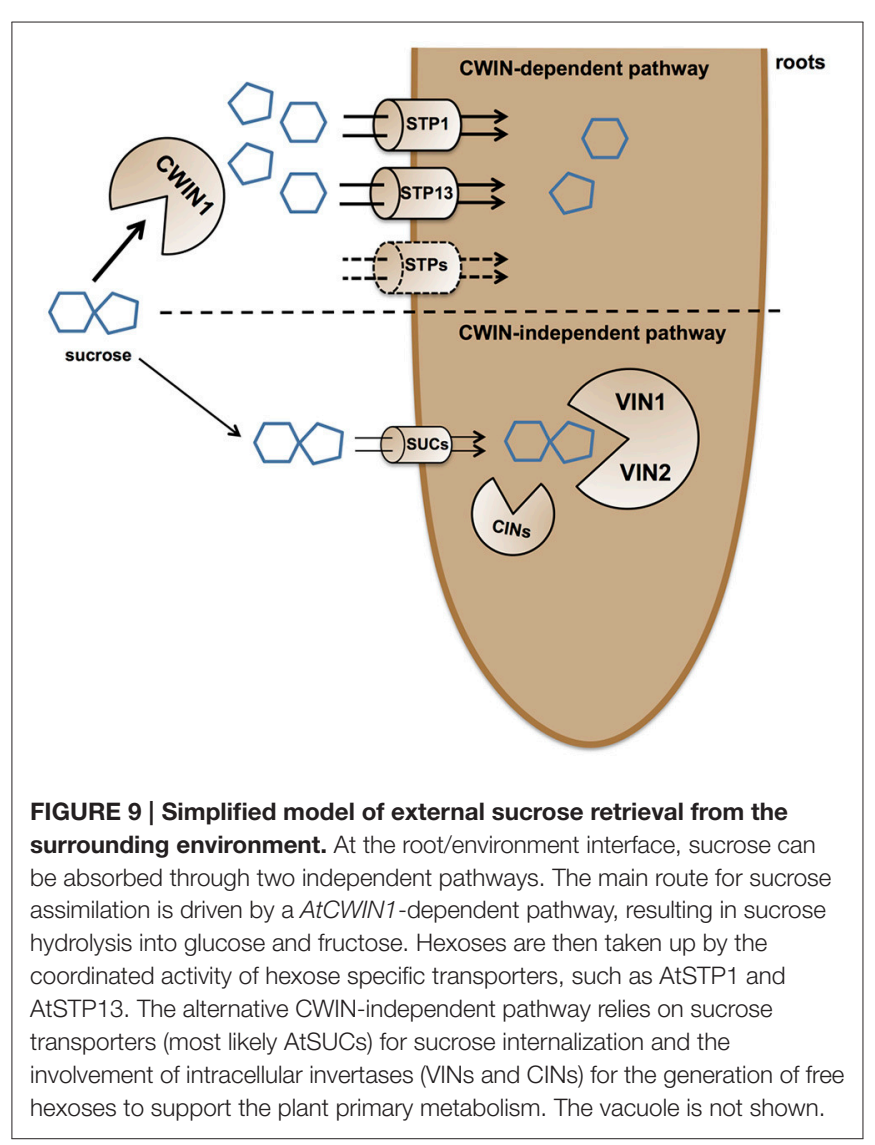


presence of the protonophore CCCP (Figure 2A). This result is different from the study using FRET glucose and sucrose sensors showing that sucrose accumulation in root tips was insensitive to protonophores, suggesting the involvement of low-affinity transporters for root tip uptake (Chaudhuri et al., 2008). As we used completely different experimental conditions (e.g., entire root system vs. root tip, radiolabeled sucrose vs. FRET sensor, sugar and CCCP concentrations), it is likely that both studies highlighted complementary processes. However, according to several reports, we found that three sucrose transporters AtSUC1, -2 , and -3 were expressed at a high level in roots supporting the probable involvement of sucrose $/ \mathrm{H}^{+}$symporters in root sucrose retrieval (Figure 2E) (Truernit and Sauer, 1995; Meyer et al., 2004; Sivitz et al., 2007, 2008; Durand et al., 2016). Therefore, it would be interesting to determine the precise role of individual AtSUC genes in sucrose uptake in future studies. The AtCWIN1independent pathway can also operate upon infection with $B$. cinerea (model in Figure 10). It was technically impossible to measure sucrose uptake in infected leaves because leaf tissues were too damaged. However, results showing that 3 AtSUC genes were expressed in both WT and cwin1-1 infected leaves, two of them being slightly induced (Figure 8), help to sustain this hypothesis.

\section{Impact of the CWIN Deficiency in Growth and Pathogen Resistance}

The inactivation of AtCWIN1 did not cause any obvious alteration of phenotype despite an almost abolished CWIN activity in both source leaves and roots. Similar observation has been reported by Quilliam et al. (2006). It suggests that the AtCWIN1-mediated activity is not essential for A. thaliana growth and development. Previous studies have reported contrasting results concerning the impact of CWIN activity on plant growth and development. For example, antisense repression of the carrot $D c C W I N 1$ gene strongly modified carbon partitioning, leading to the alteration of development, inhibition of tap root formation and enhanced foliar growth (Tang et al., 1999).

We evidenced that AtCWIN1 is unique among CWIN genes regarding its essential contribution to the CWIN activity during A. thaliana/B. cinerea interaction. However, phenotypic analysis revealed that lack of AtCWIN1 did not cause any modification of the basal resistance against B. cinerea (Figure 5). By contrast, several reports indicate that induction of CWIN activity may be required for plant resistance to pathogens (Bonfig et al., 2010; Siemens et al., 2011). The differential impact of CWIN activity in the susceptibility or resistance may be due to the difference of the pathogen lifestyle. The degradation of apoplastic sucrose by CWIN is crucial for biotrophic or hemibiotrophic pathogens as they mainly rely on the sugar acquisition from the apoplast through the activity of hexose transporters (Sutton et al., 1999; Hall and Williams, 2000; Voegele et al., 2001). As a necrotroph, B. cinerea secretes multiple cell wall-degrading enzymes that allow plant tissue colonization and the release of carbohydrates for consumption (Choquer et al., 2007). Consequently, CWIN activity may be of secondary concern for pathogen development in the case of necrotrophs. In some reports, it was also shown that during infection, CWIN activity triggers plant defense responses (Essmann et al., 2008b; Tauzin and Giardina, 2014). Because we did not observe any modification of classical defense gene expression patterns (Supplementary Figure 5), we postulate that AtCWIN1 is not essential for the activation of the PAMP-Triggered Immunity in response to $B$. cinerea. However, the precise role of free hexoses generated by the Botrytis-induced activity remains to be elucidated.

\section{Alternative Sucrose Cleavage by Intracellular Invertases}

Considering the importance of cell wall invertases in plant carbon partitioning, it was quite unexpected that cwin1-1 plants grew up normally, either in soil or in vitro. We attempted to understand how plants deal with the absence of CWIN activity. Interestingly, we found that the content of the most important soluble sugars were similar in WT and cwin1-1 leaves and roots (Supplementary Figure 4). These results strongly suggest that cwin1-1 tissues are sufficiently fuelled with hexoses by an alternative sucrolytic activity. In addition to CWINs, cytosolic (CIN) and vacuolar (VINs) invertases are important in maintaining the intracellular sugar homeostasis. Roles of CINs are less clear, probably because they are less stable proteins with low activity compared to VINs and CWINs (Pagny et al., 2003; Roitsch and González, 2004; Ruan, 2014). Therefore, we focused our analysis on vacuolar invertases known to play an essential role for normal growth (Sergeeva et al., 2006; Ruan et al., 2010; Leskow et al., 2016). Consistent with other studies, we were able to measure a transcript accumulation of VIN-encoding genes and high VIN activities in leaves and roots (Figure 3) (Quilliam et al., 2006; Sergeeva et al., 2006; Wang et al., 2010; Leskow et al., 2016; Su et al., 2016). VIN activity was operational in cwin1-1 leaves and roots, and a comparative analysis of absolute levels of sucrose degradation showed that the invertase activity was far greater in the vacuole that in the apoplast (Figures 1A, 3B).

We monitored cytoplasmic and vacuolar invertase activities in infected leaves. Interestingly, the overall intracellular invertase activity was induced in WT and cwin1-1 infected leaves, with a major contribution of VINs (Figures 6A-C). The involvement of vacuolar and cytosolic invertases in plant defense is poorly described. Sutton et al. (2007) reported that the infection of wheat leaves with powdery mildew (Blumeria graminis) induced all types of invertases. The down-regulation of a wheat alkaline/neutral invertase correlates with reduced host susceptibility to wheat stripe rust caused by Puccinia striiformis (Liu et al., 2015). Altogether, our results highlight the importance of the VIN-mediated sucrose degradation. In the absence of AtCWIN1, we postulate that sucrose might follow an alternative pathway involving sucrose transporters and VINs (Figures 9, 10). We hypothesize that the high activity of the latter pathway is sufficient to maintain the internal sugar homeostasis and may provide sufficient hexoses to fuel plant defense. In this scenario, the precise role of tonoplast sugar transporters involved in balancing cytosolic and vacuolar sugar 


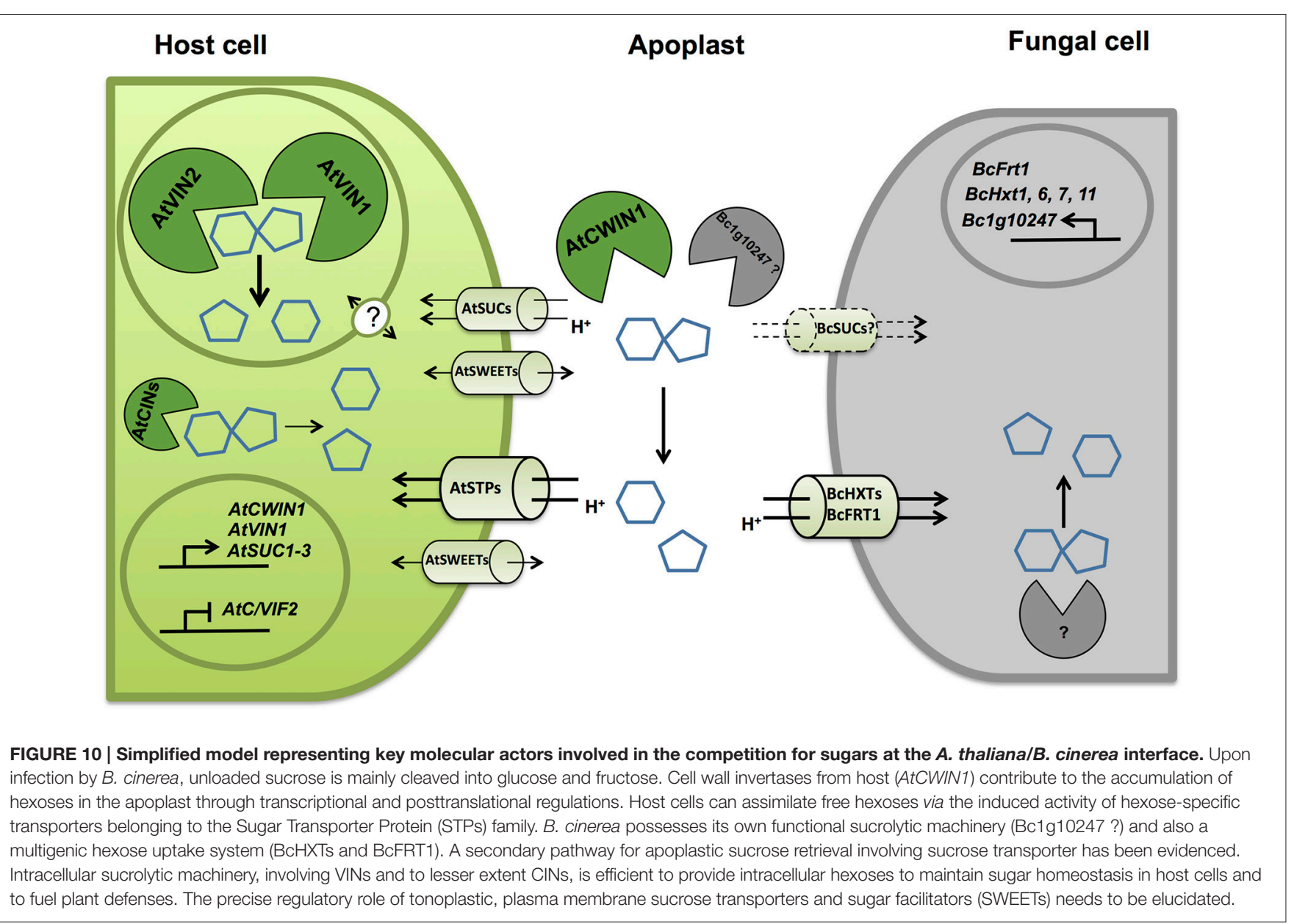

levels has to be determined (Schulz et al., 2011; Hedrich et al., 2015).

\section{Competition for Sugars at the Plant/Pathogen Interface}

The impact of the increased CWIN activity for both the host and the pathogen remains to be elucidated. On one side, it may be advantageous for the host by providing resources to defending cells (Biemelt and Sonnewald, 2006; Schultz et al., 2013). This assumption required the cooperation of CWIN and hexose transporters in order to supply host tissues with hexoses. During the biotrophic interaction between E. cichoracearum and A. thaliana, the up-regulation of AtCWIN1 and the hexose transporter AtSTP4 is correlated with the increase in invertase activity and glucose assimilation (Fotopoulos et al., 2003). In a previous study, we have reported that the high expression of the hexose transporter STP13 is associated with an increased glucose uptake activity, leading to an enhanced resistance against B. cinerea (Lemonnier et al., 2014). Since STP13 is the only member of the AtSTP family induced by the necrotrophic fungus B. cinerea (Lemonnier et al., 2014), it may have a coordinated role with AtCWIN1 to efficiently supply host cells with hexoses.

Increased CWIN activity may also be beneficial for the nutrient acquisition of the fungus since it may reduce the sucrose exported from leaves, facilitate local phloem unloading and increase the content of available apoplastic hexoses (Scharte et al., 2005). To gain insight into the strategy of carbon assimilation by $B$. cinerea, we explored the capacity of this fungus to cleave sucrose and absorb external sugars. Although all types of invertase activities were detected, our results indicate that sucrose is preferentially cleaved into hexoses prior to be internalized by an active hexose uptake system (Figures $\mathbf{8 ,}$ 10). To date, few studies have reported the characterization of fungal CWINs (Voegele et al., 2006). Regarding necrotrophs, fungal specific invertases have been detected in infected grape and sunflower infected with B. cinerea and Sclerotinia sclerotiorum, respectively (Ruiz and Ruffner, 2002; Jobic et al., 2007). In order to identify candidate genes encoding putative invertases, we have targeted genes belonging to the glycoside hydrolase family 32 in the genome of $B$. cinerea. Based on conserved motifs and expression pattern during plant infection (Figure 8D), we have identified a candidate with a putative function of cell wall invertase. The next challenge will be to characterize its activity in vitro and in vivo, and to determine its role in the sugar acquisition and fungal pathogenicity. Botrytis sucrose transporters have not been yet identified but a versatile hexose uptake system, including a high affinity fructose transporter (BcFRT1) and a multigenic family of putative hexose transporters (BcHXTs) have been described 
(Doehlemann et al., 2005; Dulermo et al., 2009). Our results showing that sugars are preferentially assimilated in the form of hexoses by the fungus are supported by the differential expression of several hexose transporters during the course of the pathogenic interaction (Figure 10).

By targeting the AtCWIN1 gene, the present study had for main purpose to explore the role of cell wall invertase activity in source and sinks organs, and upon pathogen infection using the necrotrophic fungus $B$. cinerea. We conclude that AtCWIN1 is essential for the cell wall invertase activity in diverse situations, i.e., in sink organs or in infected leaves. However, our results show that plant cells have evolved alternative mechanisms for sucrose cleavage to maintain the cellular homeostasis (Figures 9, 10). The next challenge will be to determine the precise role and regulation of the molecular actors involved in these alternative pathways. Further investigations are needed to understand more precisely the role of cell wall invertases in the competition for sugars at the plant/pathogen interface. One interesting track would be the assessment of fungal invertase and sugar transporter contributions in $B$. cinerea pathogenicity, as the fungus side in plant/pathogen interaction has retained much less attention than the plant side so far.

\section{AUTHOR CONTRIBUTIONS}

SL, PC, and FV designed the experiments. FV and CG performed the experiments. SL and FV wrote the article. SL, PC, CG, and FV

\section{REFERENCES}

Ainsworth, E. A., and Bush, D. R. (2011). Carbohydrate export from the leaf: a highly regulated process and target to enhance photosynthesis and productivity. Plant Physiol. 155, 64-69. doi: 10.1104/pp.110.167684

Alonso, J. M., Stepanova, A. N., Leisse, T. J., Kim, C. J., Chen, H., Shinn, P., et al. (2003). Genome-wide insertional mutagenesis of Arabidopsis thaliana. Science 301, 653-657. doi: 10.1126/science.1086391

Azevedo, H., Conde, C., Gerós, H., and Tavares, R. M. (2006). The nonhost pathogen Botrytis cinerea enhances glucose transport in Pinus pinaster suspension-cultured cells. Plant Cell Physiol. 47, 290-298. doi: 10.1093/pcp/ pci248

Bae, S., Park, J., and Kim, J.-S. (2014). Cas-OFFinder: a fast and versatile algorithm that searches for potential off-target sites of Cas9 RNA-guided endonucleases. Bioinformatics 30, 1473-1475. doi: 10.1093/bioinformatics/btu048

Barratt, D. H. P., Derbyshire, P., Findlay, K., Pike, M., Wellner, N., Lunn, J., et al. (2009). Normal growth of Arabidopsis requires cytosolic invertase but not sucrose synthase. Proc. Natl. Acad. Sci. U.S.A. 106, 13124-13129. doi: 10.1073/pnas.0900689106

Berger, S., Sinha, A. K., and Roitsch, T. (2007). Plant physiology meets phytopathology: plant primary metabolism and plant-pathogen interactions. J. Exp. Bot. 58, 4019-4026. doi: 10.1093/jxb/erm298

Biemelt, S., and Sonnewald, U. (2006). Plant-microbe interactions to probe regulation of plant carbon metabolism. J. Plant Physiol. 163, 307-318. doi: 10.1016/j.jplph.2005.10.011

Bolouri-Moghaddam, M. R., Le Roy, K., Xiang, L., Rolland, F., and Van den Ende, W. (2010). Sugar signalling and antioxidant network connections in plant cells. FEBS J. 277, 2022-2037. doi: 10.1111/j.1742-4658.2010.07633.x

Bolouri Moghaddam, M. R., and Van den Ende, W. (2012). Sugars and plant innate immunity. J. Exp. Bot. 63, 3989-3998. doi: 10.1093/jxb/ers129

Bolton, M. D. (2009). Primary metabolism and plant defense-fuel for the fire. Mol. Plant Microbe Interact. 22, 487-497. doi: 10.1094/MPMI-22-5-0487 discussed the data and revised the article. All authors approved the final manuscript.

\section{FUNDING}

This work was supported by the Centre National de la Recherche Scientifique, the University of Poitiers, the Région Poitou-Charentes (FV PhD grant), the State-Region Planning Contracts (CPER) and the European Regional Development Fund (FEDER).

\section{ACKNOWLEDGMENTS}

We thank Dr. Puchta and his team (Botanical Institute II, Karlsruhe Institute of Technology, Karlsruhe, Germany) for kindly providing the CRISPR/Cas9 vectors. We are grateful to Vincent Lebeurre and Bruno Faure for helping us to produce the plants used in this study, to Marina Perez Benitez for her help in the correction of the manuscript, to Cécile Vriet for help with CRISPR/Cas9 vectors, and to our colleagues for inspiring discussions.

\section{SUPPLEMENTARY MATERIAL}

The Supplementary Material for this article can be found online at: http://journal.frontiersin.org/article/10.3389/fpls.2016. 01899/full\#supplementary-material
Bonfig, K. B., Gabler, A., Simon, U. K., Luschin-Ebengreuth, N., Hatz, M., Berger, S., et al. (2010). Post-translational derepression of invertase activity in source leaves via down-regulation of invertase inhibitor expression is part of the plant defense response. Mol. Plant 3, 1037-1048. doi: 10.1093/mp/ssq053

Bonfig, K., Schreiber, U., Gabler, A., Roitsch, T., and Berger, S. (2006). Infection with virulent and avirulent $P$. syringae strains differentially affects photosynthesis and sink metabolism in Arabidopsis leaves. Planta 225, 1-12. doi: 10.1007/s00425-006-0303-3

Büttner, M. (2007). The monosaccharide transporter(-like) gene family in Arabidopsis. FEBS Lett. 581, 2318-2324. doi: 10.1016/j.febslet.2007.03.016

Büttner, M. (2010). The Arabidopsis sugar transporter (AtSTP) family: an update. Plant Biol. 12(Suppl. 1), 35-41. doi: 10.1111/j.1438-8677.2010.00383.x

Chandran, D. (2015). Co-option of developmentally regulated plant SWEET transporters for pathogen nutrition and abiotic stress tolerance. IUBMB Life 67, 461-471. doi: 10.1002/iub.1394

Chaudhuri, B., Hörmann, F., Lalonde, S., Brady, S. M., Orlando, D. A., Benfey, P., et al. (2008). Protonophore- and $\mathrm{pH}$-insensitive glucose and sucrose accumulation detected by FRET nanosensors in Arabidopsis root tips. Plant J. 56, 948-962. doi: 10.1111/j.1365-313X.2008.03652.x

Chen, L. Q., Hou, B. H., Lalonde, S., Takanaga, H., Hartung, M. L., Qu, X. Q., et al. (2010). Sugar transporters for intercellular exchange and nutrition of pathogens. Nature 468, 527-532. doi: 10.1038/nature09606

Cheng, W. H., Taliercio, E. W., and Chourey, P. S. (1996). The miniature1 seed locus of maize encodes a cell wall invertase required for normal development of endosperm and maternal cells in the pedicel. Plant Cell 8, 971-983. doi: $10.1105 /$ tpc.8.6.971

Cheng, W. H., Taliercio, E. W., and Chourey, P. S. (1999). Sugars modulate an unusual mode of control of the cell-wall invertase gene (Incw1) through its $3^{\prime}$ untranslated region in a cell suspension culture of maize. Proc. Natl. Acad. Sci. U.S.A. 96, 10512-10517

Chong, J., Piron, M. C., Meyer, S., Merdinoglu, D., Bertsch, C., and Mestre, P. (2014). The Sweet family of sugar transporters in grapevine: VvSWEET4 is 
involved in the interaction with Botrytis cinerea. J. Exp. Bot. 65, 6589-6601. doi: $10.1093 /$ jxb/eru375

Choquer, M., Fournier, E., Kunz, C., Levis, C., Pradier, J. M., Simon, A., et al. (2007). Botrytis cinerea virulence factors: new insights into a necrotrophic and polyphageous pathogen. FEMS Microbiol. Lett. 277, 1-10. doi: 10.1111/j.1574-6968.2007.00930.x

Chou, H. M., Bundock, N., Rolfe, S. A., and Scholes, J. D. (2000). Infection of Arabidopsis thaliana leaves with Albugo candida (white blister rust) causes a reprogramming of host metabolism. Mol. Plant Pathol. 1, 99-113. doi: 10.1046/j.1364-3703.2000.00013.x

Clough, S. J., and Bent, A. F. (1998). Floral dip: a simplified method for Agrobacterium-mediated transformation of Arabidopsis thaliana. Plant J. 16, 735-743. doi: 10.1046/j.1365-313x.1998.00343.x

Czechowski, T., Stitt, M., Altmann, T., Udvardi, M. K., and Scheible, W. R. (2005). Genome-wide identification and testing of superior reference genes for transcript normalization in Arabidopsis. Plant Physiol. 139, 5-17. doi: 10.1104/pp.105.063743

De Coninck, B., Le Roy, K., Francis, I., Clerens, S., Vergauwen, R., Halliday, A. M., et al. (2005). Arabidopsis AtcwINV3 and 6 are not invertases but are fructan exohydrolases (FEHs) with different substrate specificities. Plant Cell Environ. 28, 432-443. doi: 10.1111/j.1365-3040.2004.01281.x

Doehlemann, G., Molitor, F., and Hahn, M. (2005). Molecular and functional characterization of a fructose specific transporter from the gray mold fungus Botrytis cinerea. Fungal Genet. Biol. 42, 601-610. doi: 10.1016/j.fgb.2005.03.001

Doidy, J., Grace, E., Kühn, C., Simon-Plas, F., Casieri, L., and Wipf, D. (2012). Sugar transporters in plants and in their interactions with fungi. Trends Plant Sci. 17, 413-422. doi: 10.1016/j.tplants.2012.03.009

Dulermo, T., Rascle, C., Chinnici, G., Gout, E., Bligny, R., and Cotton, P. (2009). Dynamic carbon transfer during pathogenesis of sunflower by the necrotrophic fungus Botrytis cinerea: from plant hexoses to mannitol. New Phytol. 183, 1149-1162. doi: 10.1111/j.1469-8137.2009.02890.x.

Durand, M., Porcheron, B., Hennion, N., Maurousset, L., Lemoine, R., and Pourtau, N. (2016). Water deficit enhances C export to the roots in Arabidopsis thaliana plants with contribution of sucrose transporters in both shoot and roots. Plant Physiol. 170, 1460-1479. doi: 10.1104/pp.15.01926

Essmann, J., Bones, P., Weis, E., and Scharte, J. (2008a). Leaf carbohydrate metabolism during defense: intracellular sucrose-cleaving enzymes do not compensate repression of cell wall invertase. Plant Signal. Behav. 3, 885-887. doi: $10.4161 /$ psb.3.10.6501

Essmann, J., Schmitz-Thom, I., Schön, H., Sonnewald, S., Weis, E., and Scharte, J. (2008b). RNA interference-mediated repression of cell wall invertase impairs defense in source leaves of tobacco. Plant Physiol. 147, 1288-1299. doi: $10.1104 /$ pp.108.121418

Fauser, F., Schiml, S., and Puchta, H. (2014). Both CRISPR/Cas-based nucleases and nickases can be used efficiently for genome engineering in Arabidopsis thaliana. Plant J. 79, 348-359. doi: 10.1111/tpj.12554

Fotopoulos, V., Gilbert, M. J., Pittman, J. K., Marvier, A. C., Buchanan, A. J., Sauer, N., et al. (2003). The monosaccharide transporter gene, AtSTP4, and the cell-wall invertase, At $\beta$ fruct1, are induced in Arabidopsis during infection with the fungal biotroph Erysiphe cichoracearum. Plant Physiol. 132, 821-829. doi: 10.1104/pp.103.021428

Fujita, M., Fujita, Y., Noutoshi, Y., Takahashi, F., Narusaka, Y., YamaguchiShinozaki, K., et al. (2006). Crosstalk between abiotic and biotic stress responses: a current view from the points of convergence in the stress signaling networks. Curr. Opin. Plant Biol. 9, 436-442. doi: 10.1016/j.pbi.2006.05.014

Gachon, C., and Saindrenan, P. (2004). Real-time PCR monitoring of fungal development in Arabidopsis thaliana infected by Alternaria brassicicola and Botrytis cinerea. Plant Physiol. Biochem. 42, 367-371. doi: 10.1016/ j.plaphy.2004.04.001

Glazebrook, J. (2005). Contrasting mechanisms of defense against biotrophic and necrotrophic pathogens. Annu. Rev. Phytopathol. 43, 205-227. doi: 10.1146/ annurev.phyto.43.040204.135923

Hall, J. L., and Williams, L. E. (2000). Assimilate transport and partitioning in fungal biotrophic interactions. Funct. Plant Biol. 27, 549-560. doi: 10.1071/ PP99140

Hayes, M. A., Feechan, A., and Dry, I. B. (2010). Involvement of abscisic acid in the coordinated regulation of a stress-inducible hexose transporter (VvHT5) and a cell wall invertase in grapevine in response to biotrophic fungal infection. Plant Physiol. 153, 211-221. doi: 10.1104/pp.110.154765

Hedrich, R., Sauer, N., and Neuhaus, H. E. (2015). Sugar transport across the plant vacuolar membrane: nature and regulation of carrier proteins. Curr. Opin. Plant Biol. 25, 63-70. doi: 10.1016/j.pbi.2015.04.008

Herbers, K., Meuwly, P., Frommer, W. B., Metraux, J. P., and Sonnewald, U. (1996). Systemic acquired resistance mediated by the ectopic expression of invertase: possible hexose sensing in the secretory pathway. Plant Cell 8, 793-803. doi: 10.1105/tpc.8.5.793

Herbers, K., and Sonnewald, U. (1998). Molecular determinants of sink strength. Curr. Opin. Plant Biol. 1, 207-216.

Hothorn, M., Van den Ende, W., Lammens, W., Rybin, V., and Scheffzek, K. (2010). Structural insights into the $\mathrm{pH}$-controlled targeting of plant cell-wall invertase by a specific inhibitor protein. Proc. Natl. Acad. Sci. U.S.A. 107, 17427-17432. doi: 10.1073/pnas.1004481107

Jia, L., Zhang, B., Mao, C., Li, J., Wu, Y., Wu, P., et al. (2008). OsCYTINV1 for alkaline/neutral invertase is involved in root cell development and reproductivity in rice (Oryza sativa L.). Planta 228, 51-59. doi: 10.1007/ s00425-008-0718-0

Jinek, M., Chylinski, K., Fonfara, I., Hauer, M., Doudna, J. A., and Charpentier, E. (2012). A programmable dual-RNA-guided DNA endonuclease in adaptive bacterial immunity. Science 337, 816-821. doi: 10.1126/science.1225829

Jobic, C., Boisson, A. M., Gout, E., Rascle, C., Fèvre, M., Cotton, P., et al. (2007). Metabolic processes and carbon nutrient exchanges between host and pathogen sustain the disease development during sunflower infection by Sclerotinia sclerotiorum. Planta 226, 251-265. doi: 10.1007/s00425-006-0470-2

Karimi, M., Inzé, D., and Depicker, A. (2002). GATEWAYTM vectors for Agrobacterium-mediated plant transformation. Trends Plant Sci. 7, 193-195. doi: 10.1016/S1360-1385(02)02251-3

Kay, R., Chan, A., Daly, M., and McPherson, J. (1987). Duplication of CaMV 35S promoter sequences creates a strong enhancer for plant genes. Science 236, 1299-1302.

Klann, E. M., Hall, B., and Bennett, A. B. (1996). Antisense acid invertase (TIV1) gene alters soluble sugar composition and size in transgenic tomato fruit. Plant Physiol. 112, 1321-1330. doi: 10.1104/pp.112.3.1321

Koch, K. (2004). Sucrose metabolism: regulatory mechanisms and pivotal roles in sugar sensing and plant development. Curr. Opin. Plant Biol. 7, 235-246. doi: 10.1016/j.pbi.2004.03.014

Kubicek, C. P., Starr, T. L., and Glass, N. L. (2014). Plant cell wall-degrading enzymes and their secretion in plant-pathogenic fungi. Annu. Rev. Phytopathol. 52, 427-451. doi: 10.1146/annurev-phyto-102313-045831

La Camera, S., L'Haridon, F., Astier, J., Zander, M., Abou-Mansour, E., Page, G., et al. (2011). The glutaredoxin ATGRXS13 is required to facilitate Botrytis cinerea infection of Arabidopsis thaliana plants. Plant J. 68, 507-519. doi: 10.1111/j.1365-313X.2011.04706.x

Laluk, K., and Mengiste, T. (2010). Necrotroph attacks on plants: wanton destruction or covert extortion? Arabidopsis Book 8:e0136. doi: 10.1199/ tab.0136

Lemoine, R., La Camera, S., Atanassova, R., Dédaldéchamp, F., Allario, T., Pourtau, N., et al. (2013). Source to sink transport and regulation by environmental factors. Front Plant Sci 4:272. doi: 10.3389/fpls.2013.00272

Lemonnier, P., Gaillard, C., Veillet, F., Verbeke, J., Lemoine, R., Coutos-Thévenot, P., et al. (2014). Expression of Arabidopsis sugar transport protein STP13 differentially affects glucose transport activity and basal resistance to Botrytis cinerea. Plant Mol. Biol. 85, 473-484. doi: 10.1007/s11103-014-0198-5

Leskow, C. C., Kamenetzky, L., Dominguez, P. G., Díaz Zirpolo, J. A., Obata, T., Costa, H., et al. (2016). Allelic differences in a vacuolar invertase affect Arabidopsis growth at early plant development. J. Exp. Bot. 67, 4091-4103. doi: 10.1093/jxb/erw185

Lingner, U., Münch, S., Deising, H. B., and Sauer, N. (2011). Hexose transporters of a hemibiotrophic plant pathogen: functional variations and regulatory differences at different stages of infection. J. Biol. Chem. 286, 20913-20922. doi: $10.1074 /$ jbc.M110.213678

Link, M., Rausch, T., and Greiner, S. (2004). In Arabidopsis thaliana, the invertase inhibitors AtC/VIF1 and 2 exhibit distinct target enzyme specificities and expression profiles. FEBS Lett. 573, 105-109. doi: 10.1016/j.febslet.2004. 07.062 
Liu, J., Han, L., Huai, B., Zheng, P., Chang, Q., Guan, T., et al. (2015). Downregulation of a wheat alkaline/neutral invertase correlates with reduced host susceptibility to wheat stripe rust caused by Puccinia striiformis. J. Exp. Bot. 66, 7325-7338. doi: 10.1093/jxb/erv428

Meyer, S., Lauterbach, C., Niedermeier, M., Barth, I., Sjolund, R. D., and Sauer, N. (2004). Wounding enhances expression of AtSUC3, a sucrose transporter from arabidopsis sieve elements and sink tissues. Plant Physiol. 134, 684-693. doi: 10.1104/pp.103.033399

Nadwodnik, J., and Lohaus, G. (2008). Subcellular concentrations of sugar alcohols and sugars in relation to phloem translocation in Plantago major, Plantago maritima, Prunus persica, and Apium graveolens. Planta 227, 1079-1089. doi: 10.1007/s00425-007-0682-0

Norholm, M. H., Nour-Eldin, H. H., Brodersen, P., Mundy, J., and Halkier, B. A. (2006). Expression of the Arabidopsis high-affinity hexose transporter STP13 correlates with programmed cell death. FEBS Lett. 580, 2381-2387. doi: 10. 1016/j.febslet.2006.03.064

Pagny, S., Denmat-Ouisse, L.-A., Gomord, V., and Faye, L. (2003). Fusion with HDEL protects cell wall invertase from early degradation when N-glycosylation is Inhibited. Plant Cell Physiol. 44, 173-182. doi: 10.1093/pcp/pcg027

Panstruga, R. (2003). Establishing compatibility between plants and obligate biotrophic pathogens. Curr. Opin. Plant Biol. 6, 320-326. doi: 10.1016/S13695266(03)00043-8

Park, J., Bae, S., and Kim, J.-S. (2015). Cas-Designer: a web-based tool for choice of CRISPR-Cas9 target sites. Bioinformatics 31, 4014-4016. doi: 10.1093/ bioinformatics/btv537

Parrent, J. L., James, T. Y., Vasaitis, R., and Taylor, A. F. (2009). Friend or foe? Evolutionary history of glycoside hydrolase family 32 genes encoding for sucrolytic activity in fungi and its implications for plant-fungal symbioses. BMC Evol. Biol. 9:148. doi: 10.1186/1471-2148-9-148

Proels, R. K., and Hückelhoven, R. (2014). Cell-wall invertases, key enzymes in the modulation of plant metabolism during defence responses. Mol. Plant Pathol. 15, 858-864. doi: 10.1111/mpp.12139

Quilliam, R. S., Swarbrick, P. J., Scholes, J. D., and Rolfe, S. A. (2006). Imaging photosynthesis in wounded leaves of Arabidopsis thaliana. J. Exp. Bot. 57, 55-69. doi: 10.1093/jxb/erj039

Rausch, T., and Greiner, S. (2004). Plant protein inhibitors of invertases. Biochim. Biophys. Acta 1696, 253-261. doi: 10.1016/j.bbapap.2003.09.017

Roitsch, T. (1999). Source-sink regulation by sugar and stress. Curr. Opin. Plant Biol. 2, 198-206. doi: 10.1016/S1369-5266(99)80036-3

Roitsch, T., Balibrea, M. E., Hofmann, M., Proels, R., and Sinha, A. K. (2003). Extracellular invertase: key metabolic enzyme and PR protein. J. Exp. Bot. 54, 513-524. doi: 10.1093/jxb/erg050

Roitsch, T., and González, M. C. (2004). Function and regulation of plant invertases: sweet sensations. Trends Plant Sci. 9, 606-613. doi: 10.1016/ j.tplants.2004.10.009

Rolland, F., Baena-Gonzalez, E., and Sheen, J. (2006). Sugar sensing and signaling in plants: conserved and novel mechanisms. Annu. Rev. Plant Biol. 57, 675-709. doi: 10.1146/annurev.arplant.57.032905.105441

Rolland, F., Moore, B., and Sheen, J. (2002). Sugar sensing and signaling in plants. Plant Cell 14, s185-s205. doi: 10.1105/tpc.010455

Ruan, Y. L. (2014). Sucrose metabolism: gateway to diverse carbon use and sugar signaling. Annu. Rev. Plant Biol. 65, 33-67. doi: 10.1146/annurev-arplant-050213-040251

Ruan, Y.-L., Jin, Y., Yang, Y.-J., Li, G.-J., and Boyer, J. S. (2010). Sugar input, metabolism, and signaling mediated by invertase: roles in development, yield potential, and response to drought and heat. Mol. Plant 3, 942-955. doi: $10.1093 / \mathrm{mp} / \mathrm{ssq} 044$

Ruhlmann, J. M., Kram, B. W., and Carter, C. J. (2010). Cell wall invertase 4 is required for nectar production in Arabidopsis. J. Exp. Bot. 61, 395-404. doi: $10.1093 /$ jxb/erp309

Ruiz, E., and Ruffner, H. P. (2002). Immunodetection of Botrytis-specific invertase in infected grapes. J. Phytopathol. 150, 76-85. doi: 10.1046/j.1439-0434.2002. 00720.x

Sauer, N., Friedländer, K., and Gräml-Wicke, U. (1990). Primary structure, genomic organization and heterologous expression of a glucose transporter from Arabidopsis thaliana. EMBO J. 9, 3045-3050.

Scharte, J., Schön, H., and Weis, E. (2005). Photosynthesis and carbohydrate metabolism in tobacco leaves during an incompatible interaction with
Phytophthora nicotianae. Plant Cell Environ. 28, 1421-1435. doi: 10.1111/ j.1365-3040.2005.01380.x

Schmittgen, T. D., and Livak, K. J. (2008). Analyzing real-time PCR data by the comparative CT method. Nat. Protocols 3, 1101-1108. doi: 10.1038/ nprot.2008.73

Schultz, J. C., Appel, H. M., Ferrieri, A. P., and Arnold, T. M. (2013). Flexible resource allocation during plant defense responses. Front. Plant Sci. 4:324. doi: 10.3389/fpls.2013.00324

Schulz, A., Beyhl, D., Marten, I., Wormit, A., Neuhaus, E., Poschet, G., et al. (2011). Proton-driven sucrose symport and antiport are provided by the vacuolar transporters SUC4 and TMT1/2. Plant J. 68, 129-136. doi: 10.1111/ j.1365-313X.2011.04672.x

Sergeeva, L. I., Keurentjes, J. J., Bentsink, L., Vonk, J., van der Plas, L. H., Koornneef, M., et al. (2006). Vacuolar invertase regulates elongation of Arabidopsis thaliana roots as revealed by QTL and mutant analysis. Proc. Natl. Acad. Sci. U.S.A. 103, 2994-2999. doi: 10.1073/pnas.0511015103

Sherson, S. M., Alford, H. L., Forbes, S. M., Wallace, G., and Smith, S. M. (2003). Roles of cell-wall invertases and monosaccharide transporters in the growth and development of Arabidopsis. J. Exp. Bot. 54, 525-531. doi: 10.1093/jxb/erg055

Siemens, J., González, M. C., Wolf, S., Hofmann, C., Greiner, S., Du, Y., et al. (2011). Extracellular invertase is involved in the regulation of clubroot disease in Arabidopsis thaliana. Mol. Plant Pathol. 12, 247-262. doi: 10.1111/j.1364-3703.2010.00667.x

Sivitz, A. B., Reinders, A., Johnson, M. E., Krentz, A. D., Grof, C. P., Perroux, J. M., et al. (2007). Arabidopsis sucrose transporter AtSUC9. High-affinity transport activity, intragenic control of expression, and early flowering mutant phenotype. Plant Physiol. 143, 188-198. doi: 10.1104/pp.106.089003

Sivitz, A. B., Reinders, A., and Ward, J. M. (2008). Arabidopsis sucrose transporter AtSUC1 is important for pollen germination and sucrose-induced anthocyanin accumulation. Plant Physiol. 147, 92-100. doi: 10.1104/pp.108. 118992

Sonnewald, S., Priller, J. P., Schuster, J., Glickmann, E., Hajirezaei, M. R., Siebig, S., et al. (2012). Regulation of cell wall-bound invertase in pepper leaves by Xanthomonas campestris pv. vesicatoria type three effectors. PLoS ONE 7:e51763. doi: 10.1371/journal.pone.0051763

Staats, M., and van Kan, J. A. L. (2012). Genome update of Botrytis cinerea strains B05.10 and T4. Eukaryot. Cell 11, 1413-1414. doi: 10.1128/ec.00164-12

Stadler, R., and Sauer, N. (1996). The Arabidopsis thaliana AtSUC2 gene is specifically expressed in companion cells. Bot. Acta 109, 299-306. doi: 10.1111/j.1438-8677.1996.tb00577.x

Stadler, R., Truernit, E., Gahrtz, M., and Sauer, N. (1999). The AtSUC1 sucrose carrier may represent the osmotic driving force for anther dehiscence and pollen tube growth in Arabidopsis. Plant J. 19, 269-278. doi: 10.1046/j.1365-313X.1999.00527.x

Su, T., Wolf, S., Han, M., Zhao, H., Wei, H., Greiner, S., et al. (2016). Reassessment of an Arabidopsis cell wall invertase inhibitor AtCIF1 reveals its role in seed germination and early seedling growth. Plant Mol. Biol. 90, 137-155. doi: 10.1007/s11103-015-0402-2

Sun, L., Yang, D.-L., Kong, Y., Chen, Y., Li, X.-Z., Zeng, L.-J., et al. (2014). Sugar homeostasis mediated by cell wall invertase Grain Incomplete Filling 1 (GIF1) plays a role in pre-existing and induced defence in rice. Mol. Plant Pathol. 15, 161-173. doi: $10.1111 / \mathrm{mpp} .12078$

Sutton, P. N., Gilbert, M. J., Williams, L. E., and Hall, J. L. (2007). Powdery mildew infection of wheat leaves changes host solute transport and invertase activity. Physiol. Plant. 129, 787-795. doi: 10.1111/j.1399-3054.2007.00863.x

Sutton, P. N., Henry, M. J., and Hall, J. L. (1999). Glucose, and not sucrose, is transported from wheat to wheat powdery mildew. Planta 208, 426-430.

Tang, G. Q., Lüscher, M., and Sturm, A. (1999). Antisense repression of vacuolar and cell wall invertase in transgenic carrot alters early plant development and sucrose partitioning. Plant Cell 11, 177-189.

Tauzin, A. S., and Giardina, T. (2014). Sucrose and invertases, a part of the plant defense response to the biotic stresses. Front. Plant Sci. 5:293. doi: $10.3389 /$ fpls.2014.00293

Truernit, E., and Sauer, N. (1995). The promoter of the Arabidopsis thaliana SUC2 sucrose- $\mathrm{H}^{+}$symporter gene directs expression of $\beta$-glucuronidase to the phloem: evidence for phloem loading and unloading by SUC2. Planta 196, 564-570. 
Untergasser, A., Cutcutache, I., Koressaar, T., Ye, J., Faircloth, B. C., Remm, M., et al. (2012). Primer3-new capabilities and interfaces. Nucleic Acids Res. 40:e115. doi: 10.1093/nar/gks596

van Kan, J. A. (2006). Licensed to kill: the lifestyle of a necrotrophic plant pathogen. Trends Plant Sci. 11, 247-253. doi: 10.1016/j.tplants.2006.03.005

Voegele, R., and Mendgen, K. (2011). Nutrient uptake in rust fungi: how sweet is parasitic life? Euphytica 179, 41-55. doi: 10.1007/s10681-011-0358-5

Voegele, R. T., Struck, C., Hahn, M., and Mendgen, K. (2001). The role of haustoria in sugar supply during infection of broad bean by the rust fungus Uromyces fabae. Proc. Natl. Acad. Sci. U.S.A. 98, 8133-8138. doi: 10.1073/pnas.131186798

Voegele, R. T., Wirsel, S., Möll, U., Lechner, M., and Mendgen, K. (2006). Cloning and characterization of a novel invertase from the obligate biotroph Uromyces fabae and analysis of expression patterns of host and pathogen invertases in the course of infection. Mol. Plant Microbe Interact .19, 625-634. doi: 10.1094/MPMI-19-0625

von Malek, B., van der Graaff, E., Schneitz, K., and Keller, B. (2002). The Arabidopsis male-sterile mutant dde2-2 is defective in the ALLENE OXIDE SYNTHASE gene encoding one of the key enzymes of the jasmonic acid biosynthesis pathway. Planta 216, 187-192. doi: 10.1007/s00425-0020906-2

Wang, E., Wang, J., Zhu, X., Hao, W., Wang, L., Li, Q., et al. (2008). Control of rice grain-filling and yeld by a gene with a potential signature of domestication. Nat Genet 40, 1370-1374. doi: 10.1038/ng.220

Wang, L., Li, X.-R., Lian, H., Ni, D.-A., He, Y. K., Chen, X.-Y., et al. (2010). Evidence that high activity of vacuolar invertase is required for cotton fiber and Arabidopsis root elongation through osmotic dependent and independent pathways, respectively. Plant Physiol. 154, 744-756. doi: 10.1104/pp.110.162487

Wang, L., and Ruan, Y.-L. (2012). New insights into roles of cell wall invertase in early seed development revealed by comprehensive spatial and temporal expression patterns of GhCWIN1 in cotton. Plant Physiol. 160, 777-787. doi: $10.1104 /$ pp.112.203893
Welham, T., Pike, J., Horst, I., Flemetakis, E., Katinakis, P., Kaneko, T., et al. (2009). A cytosolic invertase is required for normal growth and cell development in the model legume, Lotus japonicus. J. Exp. Bot. 60, 3353-3365. doi: 10.1093/jxb/erp169

Wolf, S., Kalman-Rotem, N., Yakir, D., and Zrv, M. (1998). Autotrophic and heterotrophic carbon assimilation of in vitro grown potato (Solanum tuberosum L) plants. J. Plant Physiol. 153, 574-580. doi: 10.1016/S0176-1617(98)80206-X

Xie, K., Zhang, J., and Yang, Y. (2014). Genome-wide prediction of highly specific guide RNA spacers for CRISPR-Cas9-mediated genome editing in model plants and major crops. Mol. Plant 7, 923-926. doi: 10.1093/mp/ssu009

Yamada, K., Kanai, M., Osakabe, Y., Ohiraki, H., Shinozaki, K., and YamaguchiShinozaki, K. (2011). Monosaccharide absorption activity of Arabidopsis roots depends on expression profiles of transporter genes under high salinity conditions. J. Biol. Chem. 286, 43577-43586. doi: 10.1074/jbc.m111.269712

Zanor, M. I., Osorio, S., Nunes-Nesi, A., Carrari, F., Lohse, M., Usadel, B., et al. (2009). RNA interference of LIN5 in tomato confirms its role in controlling brix content, uncovers the influence of sugars on the levels of fruit hormones, and demonstrates the importance of sucrose cleavage for normal fruit development and fertility. Plant Physiol. 150, 1204-1218. doi: 10.1104/pp.109.136598

Conflict of Interest Statement: The authors declare that the research was conducted in the absence of any commercial or financial relationships that could be construed as a potential conflict of interest.

Copyright (C) 2016 Veillet, Gaillard, Coutos-Thévenot and La Camera. This is an open-access article distributed under the terms of the Creative Commons Attribution License (CC BY). The use, distribution or reproduction in other forums is permitted, provided the original author(s) or licensor are credited and that the original publication in this journal is cited, in accordance with accepted academic practice. No use, distribution or reproduction is permitted which does not comply with these terms. 